\title{
Implications of the EU Emissions Trading System for the South-East Europe Regional Electricity Market
}

\author{
Verena Viškovića ${ }^{\text {, Yihsu Chen }}{ }^{\mathrm{c}}$, Afzal S. Siddiqui ${ }^{\mathrm{a}, \mathrm{b}, \mathrm{d}}$ \\ ${ }^{a}$ Department of Statistical Science, University College London \\ ${ }^{b}$ Department of Computer and Systems Sciences, Stockholm University \\ ${ }^{c}$ Department of Technology and Information Management, University of California Santa Cruz \\ ${ }^{d}$ Department of Decision Sciences, HEC Montréal
}

\begin{abstract}
As part of its climate policy, the European Union (EU) aims to reduce greenhouse gas (GHG) emissions levels by $20 \%$ by the year 2020 compared to 1990 levels. Although the EU is projected to reach this goal, its achievement of objectives under its Emissions Trading System (ETS) may be delayed by carbon leakage, which is defined as a situation in which the reduction in emissions in the ETS region is partially offset by an increase in carbon emissions in the non-ETS regions. We study the interaction between emissions and hydropower availability in order to estimate the magnitude of carbon leakage in the South-East Europe Regional Electricity Market (SEE-REM) via a bottom-up partial equilibrium framework. We find that $6.3 \%$ to $40.5 \%$ of the emissions reduction achieved in the ETS part of SEE-REM could be leaked to the non-ETS part depending on the price of allowances. Somewhat surprisingly, greater hydropower availability may increase emissions in the ETS part of SEE-REM. However, carbon leakage might be limited by demand response to higher electricity prices in the nonETS area of SEE-REM. Such carbon leakage can affect both the competitiveness of producers in ETS member countries on the periphery of the ETS and the achievement of EU targets for $\mathrm{CO}_{2}$ emissions reduction. Meanwhile, higher non-ETS electricity prices imply that the current policy can have undesirable outcomes for consumers in non-ETS countries, while non-ETS producers would experience an increase in their profits due to higher power prices as well as
\end{abstract}

Email addresses: verena.viskovic.13@ucl.ac.uk (Verena Višković), yihsuchen@ucsc.edu (Yihsu Chen), afzal.siddiqui@ucl.ac.uk (Afzal S. Siddiqui) 
exports. The presence of carbon leakage in SEE-REM suggests that current EU policy might become more effective when it is expanded to cover more countries in the future. Keywords: Carbon leakage, $\mathrm{CO}_{2}$ emissions, EU ETS, Energy Community

\section{Introduction}

Convincing evidence provided by the most recent IPCC report suggests that human activity is causing climate change (Stocker et al., 2013). Regardless of whether the energy sector is vertically integrated or deregulated, policymakers have implemented several measures to facilitate the reduction of greenhouse gas (GHG) emissions using both market-based mechanisms, e.g., taxes, subsidies, and emissions trading, and other policy instruments, e.g., voluntary agreements and regulatory protocols. ${ }^{1}$ An example of legally binding GHG emissions controls is the 20-20-20 targets $^{2}$ set by the European Union (EU). One of the EU 20-20-20 targets is the reduction in GHG emissions by $20 \%$ by the year 2020 compared to those in 1990 (EC, 2007). In order to facilitate this transition, the EU launched its Emissions Trading System (ETS) as a market-based mechanism in 2005. The ETS is a cap-and-trade (C\&T) system that sets a cap on aggregated emissions, and companies receive or buy tradeable emissions allowances within the cap. The cap is reduced over time in order to curb emissions. Today, it is the most extensive international system for emissions trading covering 11,000 power stations, industrial plants, and airlines in 31 countries (EC, 2015).

The trading of $\mathrm{CO}_{2}$ allowances represents an increased cost for both electricity producers and energy-intensive industries. If either such industries were to move their production to

\footnotetext{
${ }^{1}$ Whether deregulation of the power sector makes it easier for the government to reduce GHG emissions remains debatable. On the one hand, the lock-in of sunk capital by incumbents under the regulated paradigm has been viewed as a barrier to environmental policies so that deregulation is typically associated with the adoption of new technology. For example, an empirical study by Hyman (2010) suggests that a significant investment in gas-fired facilities in the U.K. was undertaken after restructuring. Indeed, recent expansion of distributed energy resources seemingly suggests that deregulation is more likely to lead to emissions reduction when mandated by the government via market-based instruments (von Hirschhausen, 2014). On the other hand, Wilson (2002) argues that the traditional vertically integrated paradigm is more likely to enforce policy due to its tighter regulation and a more involved role for the state.

${ }^{2}$ EU 20-20-20 refers to the EUs three climate targets to be reached by 2020 . First, $20 \%$ reduction in GHGs compared to 1990 levels. Second, 20\% improvements in energy efficiency relative to 1990 levels. Third, 20\% of EU energy to be produced from renewables.
} 
countries with less-strict climate policies (EC, 2009; Chen, 2009) or the countries in the regulated area were to increase their imports from non-regulated areas (Chen, 2009), then so-called "carbon leakage" would result. Thus, perversely, a C\&T system could lead to an increase in $\mathrm{CO}_{2}$ emissions in the non-regulated areas (Chen, 2009). Electricity generation in the EU ETS is for the most part covered without the possibility of leakage with the exception of some borders with non-regulated areas like in South-East Europe. In particular, the South-East Europe Regional Electricity Market (SEE-REM) comprises countries that are part of the EU and may partly offset the emission reductions from domestic production with imports from non-regulated neighbouring countries. The potential for such carbon leakage to occur as a consequence of the EU ETS in the context of SEE-REM has received little attention in the literature.

Carbon leakage might delay the achievement of environmental objectives such as EU 20-20-20 by reducing allowance prices so that producers have less than anticipated incentive to switch to less-polluting sources of power generation or to implement carbon-reduction technologies in conventional sources (Višković et al., 2014) than they would otherwise. While reducing domestic emissions, the EU ETS does not account for increased emissions in the non-regulated area that result from increased exports from the non-ETS to the ETS area in order to meet ETS electricity demand.

We use a stylised 22-node network to model the electricity sector and associated emissions of SEE-REM comprising neighbouring countries with inconsistent $\mathrm{CO}_{2}$ emissions reduction regulation (i.e., only some countries are covered by the EU ETS). The model estimates the magnitude of leakage (in percentage terms) relative to the emissions from the ETS $^{3}$ part of SEE-REM in the short term before any adjustment in capacity can occur with consideration of the impacts of hydropower availability on market outcomes. Under this framework, we

\footnotetext{
${ }^{3}$ The International Energy Agency (IEA) publishes one figure for both electricity and heat sectors. Thus, it is not straightforward to obtain an estimate of electricity sector emissions only for the entire EU ETS. However, according to the IEA, the emissions from electricity and heat generation of the countries modelled in SEE-REM were approximately $23 \%$ of the electricity and heat generation emissions of the whole EU ETS in 2013 (IEA, 2015).
} 
treat both availability of hydropower and allowance prices exogenously, thereby not allowing for 1) possible impact of hydro availability on the allowance price or 2) changing dispatch of hydropower in response to the allowance price. Parametric treatment of allowance prices is equivalent to treating the allowance price as a carbon tax, determined by the larger ETS area where the allowances are initially allocated through auction. Given that we have a fixed cap under the C\&T, our assumption implies that the increase of SEE-REM emissions covered by ETS would be offset elsewhere in the wider ETS not covered in our model.

There are three central findings resulting from our study: (i) emissions leaked into the non-ETS area could amount to $6.3 \%$ to $40.5 \%$ of the emissions reduction in the SEE-REM ETS area; ${ }^{4}$ (ii) higher electricity prices in some non-ETS countries could mitigate leakage due to non-ETS demand response that lowers consumption; and (iii) higher $\mathrm{CO}_{2}$ emissions could occur in the ETS area of SEE-REM as a result of demand response to lower electricity prices from higher availability of cheap hydropower throughout the entire SEE-REM. Moreover, the results observed under (i) and (ii) suggest a need for a more careful assessment of what to consider as $\mathrm{CO}_{2}$ emissions within the ETS, i.e., the regulator should also take into account the imports into the ETS area as part of the $\mathrm{CO}_{2}$ emissions produced by the EU and decide whether imports should be subject to the C\&T regime. However, our findings highlight the benefit of expanding the EU ETS to neighbouring countries within a regional electricity market in order to maximise the effectiveness of the program. We believe that the EU ETS paves a promising pathway to enhancing the coverage of the program.

The structure of this paper is as follows. Section 2 reviews the literature to put our work into context. Section 3 formulates the equilibrium problem. Section 4 introduces the data sources, calibrates the SEE-REM model, and presents the results of the case studies. Section 5 summarises the paper's contributions and provides directions for future research.

\footnotetext{
${ }^{4}$ The level of leakage to the non-ETS part of SEE-REM is equivalent to approximately $0.5 \%$ of electricity and heating emissions of the entire EU ETS. We obtain this figure by dividing our average estimated increase in $\mathrm{CO}_{2}$ emissions in the non-ETS part of SEE-REM $(6.5 \mathrm{Mt})$ as a result of a positive $\mathrm{CO}_{2}$ price by the total EU ETS electricity and heating emissions (1256.2 Mt).
} 


\section{Literature Review}

Up until the 1970s, least-cost methods were adequate for supporting decisions in the electric power system due to tight regulation of the electricity industry. Hobbs (1995) points out that with deregulation and unbundling, there is a need for optimisation models that account better for endogenous price formation and strategic interactions in electricity markets. Starting from Hobbs (2001), complementarity models have evolved to analyse deregulated electricity industries (Gabriel et al., 2012).

Concerns about environmental issues in the past decade have increased the need for policy-enabling models. Such models have illustrated that mechanisms such as C\&T and renewable portfolio standards (RPS) do not always work as intended (Tanaka and Chen, 2013). For instance, Limpaitoon et al. (2011) study the impact of the C\&T mechanism on electricity markets in the presence of transmission congestion and strategic behaviour. They find the possibility of less-polluting firms' exercise of market power in electricity markets by withholding supply or over-consuming permits, leading to higher electricity and permit prices. Inflated permit prices translate into a higher abatement cost for more-polluting firms. Those relatively dirty firms then decrease their generation and surrender their market share to "cleaner" firms, which results in "cleaner" firms' earning higher profits (Chen and Hobbs, 2005; Limpaitoon et al., 2014). The deployment of such strategies is supported by empirical evidence. Kolstad and Wolak (2003) find that firms manipulated the nitrogen oxides $\left(\mathrm{NO}_{x}\right)$ pollutant market in the Los Angeles metropolitan area as a way of exercising market power in the California electricity market. Specifically, the analysis suggests that some firms with a number of their generation units located in the area covered by the $\mathrm{NO}_{x}$ market deliberately paid higher prices for the permits in the years 2000 and 2001 in order to be able to justify higher offers into the California market for all electricity they produced. The result was higher electricity prices in California over 2000 and 2001.

An emission tax could also interact with power transmission in a surprising way. For instance, Downward (2010) reports that a carbon tax could cause changes in the merit order 
and reverse flow direction that could result in higher emissions in the regulated area. An increase in emissions in the regulated area is possible under a carbon tax in very specific circumstances because, unlike a C\&T, a carbon tax does not impose a cap on emissions; rather it aims to reduce emissions only through increasing abatement cost. Thus, unlike a carbon tax, the cap in a C\&T system should guarantee that an increase in domestic emissions does not happen. However, in the presence of a C\&T, increased emissions could occur outside of the regulated area, thereby causing emission leakage. ${ }^{5}$

Carbon leakage also occurs in other C\&T programs. In the context of the Regional Greenhouse Gas Initiative (RGGI), Burtraw et al. (2006) find that carbon leakage could lead to an increase in profits earned by generating facilities located outside of the regulated region. A large part of these higher profits is due to the increased electricity prices paid by consumers outside of the regulated area, suggesting that the incurred emission cost is more than offset by increased profits earned from the non-regulated region. Further considering RGGI, Palmer et al. (2006) find that although individually some firms could lose value, the electricity sector in the North-East U.S., on aggregate, could gain value because the change in revenues through a higher power price is greater than the change in emission costs. A large portion of the aggregate gain in value results from assets located outside of the regulated area, suggesting incidence of the C\&T policy on consumers outside of the C\&T region. In addition, Chen (2009) quantifies the magnitude of carbon leakage in the short term under RGGI. The paper finds that emissions in the non-regulated area might increase with a higher allowance price; however, for the same allowance prices, relative leakage might decrease.

In the context of California C\&T, as one of the possible solutions for mitigating leakage, the California Air Resource Board (CARB) introduced the obligation to report emissions

\footnotetext{
${ }^{5}$ The EU adopts a narrower definition in which carbon leakage refers only to an increase in non-regulated area emissions resulting from relocation of industry to the non-regulated area (EC, 2009). We adopt the broader definition used by (Chen, 2009) in our analysis: carbon leakage is defined as a displacement of $\mathrm{CO}_{2}$ emissions from a regulated to a non-regulated area as a consequence of imposing a carbon-reduction policy in the regulated area.
} 
associated with imports into California, the so-called "first deliverer" policy. ${ }^{6}$ Bushnell et al. (2014) find that even with a default emissions rate for imported emissions, the "first deliverer" policy could still lead to emissions leakage in the Western Electricity Coordinating Council (WECC) context through contract reshuffling.

While the relevant authorities in the US are trying to tackle the problem of carbon leakage by proposing solutions such as the "first deliverer" policy, to the best of our knowledge, the possibility of carbon leakage in SEE-REM in relation to the EU ETS has not yet been carefully examined. Although there are numerous studies examining the EU ETS, such as its impact on electricity prices and emissions (Chen et al., 2008) and the interaction between the deployment of renewable energy and the $\mathrm{CO}_{2}$ price (Weigt et al., 2013; Van den Bergh et al., 2013), our contribution is to examine the extent of carbon leakage in electricity markets under the EU ETS when considering the effect of hydropower availability.

\section{Mathematical Formulation}

\subsection{Assumptions}

We model the electricity industry via a bottom-up partial equilibrium approach in which three players are considered: producers, consumers, and a grid owner. Such a model can be implemented computationally both as a single optimisation problem and as a mixed complementarity problem (MCP) in which each entity's optimisation is addressed separately. In this paper, we choose the latter approach based on Hobbs (2001).

Producers are modelled as being price takers. Each producer owns a number of generating units located at different nodes, which are characterised by their marginal costs of production, $C_{i, n}$, and a $\mathrm{CO}_{2}$ emissions rate based on different technologies, ${ }^{7} E_{i, n}$. Moreover, each producer's objective is to maximise its profit subject to constraints related to maximum generation

\footnotetext{
${ }^{6}$ The "first deliverer" policy requires importers of electricity into California to report and pay for the associated emissions. These emissions can be based either on actual plant-specific emissions or on a default emissions factor established by the CARB.

${ }^{7}$ Note that we separate ownership based on technology, e.g., all lignite-fired units will be owned by the same firm. Therefore, we use the same index $i$ to distinguish between firms and technologies.
} 
capacity, energy balance, and non-negative quantities. Finally, each producer takes capacity, $X_{i, n}^{M A X}$, as fixed and decides how to operate generating units that it owns during each time block.

Consumers are represented by the inverse demand function at each node, $D_{t, m}^{i n t}-D_{t, m}^{s l p} \sum_{j} s_{t, j, m}$, which could be viewed as the result of solving their utility-maximisation problems. $D_{t, m}^{\text {int }}$ and $D_{t, m}^{s l p}$ are the inverse demand intercept and slope, respectively, and $\sum_{j} s_{t, j, m}$ is the electricity sold by all firms at each node in each time period, which is equivalent to the demanded quantity at each node in each time period. The grid owner's profit is given by charging a wheeling fee for power transmitted through the grid. In a sense, it optimally allocates scarce transmission resources while being constrained by the maximum transmission capacity on the lines and Kirchhoff's laws. As is common in power system economics, flows on the lines are modelled using the DC load-flow model. We have one market-clearing condition for the electricity market, which equates the difference between sales and generation with net imports at each node. Finally, the MCP is given by the set of equations representing producers' and the grid owner's Karush-Kuhn-Tucker (KKT) conditions and the market-clearing condition (Gabriel et al., 2012). The solution to this MCP exists, is unique, and represents the Nash equilibrium (Hobbs, 2001). The rest of this section is dedicated to a detailed description of each player's optimisation problem. Appendix A provides the associated nomenclature.

\subsection{Producer i's Optimisation Problem and KKT conditions}

Producer $i$ 's optimisation problem is given by (1)-(4). Specifically, producer $i$ maximises its annual profit in (1) subject to maximum capacity (2), energy-balance (3), and sales and generation non-negativity (4) constraints. Profit is given by the difference between revenue from sales and generation cost. Revenue in every time block $t$ derives from quantities sold at each node, $s_{t, i, n}$, multiplied by the electricity price at node $n,\left(D_{t, m}^{i n t}-D_{t, m}^{s l p} \sum_{j} s_{t, j, m}\right)$. The generation cost in every time block $t$ is given by quantities produced, $x_{t, i, n}$, multiplied by the marginal cost of generation, $C_{i, n}$, and wheeling fee, $\tau_{t, n}$. The wheeling fee is a transmissionbased fee, and it is calculated on the basis of transmitting power from node $n$ to node $m$ 
through an arbitrary node that acts like a hub. Specifically, the grid owner pays the wheeling fee $\tau_{t, n}$ to the producer to transmit power from node $n$ to the hub and charges the producer the wheeling fee $\tau_{t, m}$ to transmit power from the hub to node $m$ (Hobbs, 2001). Thus, the actual cost of transmission for the producer for transmitting of power from node $n$ to node $m$ is given by $\tau_{t, m}-\tau_{t, n}$. Producers in the ETS area have an additional cost due to emissions and are distinguished by the binary parameter, $T_{n}$. The emissions cost is given by the quantities produced multiplied by emissions intensity rate, $E_{i, n}$, and the cost of $\mathrm{CO}_{2}$ emissions, $R$. In order to calculate the annual profit, we multiply profit in every time block with the number of hours, $N_{t}$, that belong to that time block and sum over all $t$.

$$
\begin{aligned}
\max _{t, i, m}, x_{t, i, n} & \sum_{t} N_{t}\left(\sum_{m}\left[\left(D_{t, m}^{i n t}-D_{t, m}^{s l p} \sum_{j} s_{t, j, m}\right)-\tau_{t, m}\right] s_{t, i, m}\right. \\
& \left.-\sum_{n}\left(C_{i, n}-\tau_{t, n}\right) x_{t, i, n}-\sum_{n} T_{n} x_{t, i, n} E_{i, n} R\right) \\
\text { s.t. } & x_{t, i, n}-X_{i, n}^{M A X} \leq 0 \quad\left(\lambda_{t, i, n}\right) \quad \forall t, n \\
& \sum_{n} s_{t, i, n}-\sum_{n} x_{t, i, n}=0 \quad\left(\theta_{t, i}\right) \quad \forall t \\
& s_{t, i, n} \geq 0, x_{t, i, n} \geq 0 \quad \forall t, n
\end{aligned}
$$

The KKT conditions for producer $i$ 's optimisation problem are given in Equations (5)-(8), of which (5)-(7) are complementary slackness conditions. In particular, (5) states that if sales are equal to zero, then the revenue from sales is less than the rent on generation. Equation (6) states that if generation is equal to zero, then the rent on generation is less than the cost of generation and the shadow price of generation capacity. Finally, in (7), if the shadow price on maximum generation capacity is zero, then the maximum generation capacity constraint is not binding.

$$
0 \leq s_{t, i, m} \perp N_{t}\left(D_{t, m}^{i n t}-D_{t, m}^{s l p} \sum_{j} s_{t, j, m}-\tau_{t, m}\right)-\theta_{t, i} \leq 0 \quad \forall t, i, m
$$




$$
\begin{aligned}
& 0 \leq x_{t, i, n} \perp N_{t}\left(-C_{i, n}-T_{n} E_{i, n} R+\tau_{t, n}\right)-\lambda_{t, i, n}+\theta_{t, i} \leq 0 \quad \forall t, i, n \\
& 0 \leq \lambda_{t, i, n} \perp x_{t, i, n}-X_{i, n}^{M A X} \leq 0 \quad \forall t, i, n \\
& \sum_{m} s_{t, i, m}-\sum_{n} x_{t, i, n}=0 \quad\left(\theta_{t, i} \text { free }\right) \forall t, i
\end{aligned}
$$

\subsection{The Grid Owner's Optimisation Problem and KKT conditions}

The grid owner maximises its annual profit (9) subject to constraints given by the physical laws that apply to electricity flows (10)-(12). The grid owner's profit in every time block $t$ is the product of the wheeling fee, exogenous to the grid owner, and the net import at each node. The net import at every node is the difference between power flowing to and from that node, and this difference is obtained from the product of the power flows on the lines connected to that node and the incidence matrix, $A_{n, \ell}$. In order to obtain the annual profit, we multiply the profit from every time block $t$ by $N_{t}$ and sum over all $t$. According to the DC load-flow approximation, flows on AC lines, $f_{t, \ell A C}, \ell^{A C} \in \mathcal{L}^{A C}$, are defined in (10) and are given by the product of the network transfer matrix, $H_{n^{A C}, \ell^{A C}}$, and voltage angles, $d_{t, n^{A C}}$ (Gabriel and Leuthold, 2010; Bjørndal et al., 2013). Flows on all lines are subject to lower and upper thermal limits, $K_{\ell}$, given in (11) and (12), respectively.

$$
\begin{aligned}
\max _{d_{t, n}, f_{t, \ell}} & \sum_{t} N_{t}\left(\sum_{n} \tau_{t, n}\left(-\sum_{\ell \in \mathcal{L}} A_{n, \ell} f_{t, \ell}\right)\right) \\
\text { s.t. } f_{t, \ell} A C & =\sum_{n^{A C} \in \mathcal{N}^{A C}} H_{n^{A C}, \ell^{A C}} d_{t, n^{A C}} \quad\left(\gamma_{t, \ell^{A C}}\right), \quad \forall t, \ell^{A C} \in \mathcal{L}^{A C} \\
& -f_{t, \ell}-K_{\ell} \leq 0 \quad\left(\mu_{t, \ell}^{-} \geq 0\right), \quad \forall t, \ell \\
& f_{t, \ell}-K_{\ell} \leq 0 \quad\left(\mu_{t, \ell}^{+} \geq 0\right), \quad \forall t, \ell
\end{aligned}
$$

The KKT conditions of the grid owner's optimisation problem are given in (13a)-(17). Equations (13a)-(13b) state that the revenue of the grid owner on line $\ell$ is equal to the shadow prices on the transmission capacity of that line. Shadow prices on transmission capacity, based on the direction of the flow, are dual variables of (16) and (17) where the constraint is 
not binding if the dual is zero.

$$
\begin{gathered}
-N_{t}\left(\sum_{n} \tau_{t, n} A_{n, \ell^{A C}}\right)-\gamma_{t, \ell^{A C}}+\mu_{t, \ell^{A C}}^{-}-\mu_{t, \ell^{A C}}^{+}=0 \quad\left(f_{t, \ell^{A C}} \text { free }\right) \quad \forall t, \ell^{A C} \in \mathcal{L}^{A C} \\
-N_{t}\left(\sum_{n} \tau_{t, n} A_{n, \ell}\right)+\mu_{t, \ell}^{-}-\mu_{t, \ell}^{+}=0 \quad\left(f_{t, \ell} \text { free }\right) \quad \forall t, \ell \in \mathcal{L} \backslash \mathcal{L}^{A C} \\
\sum_{\ell^{A C} \in \mathcal{L}^{A C}} H_{\ell^{A C}, n^{A C}} \gamma_{t, \ell^{A C}}=0 \quad\left(d_{t, n^{A C}} \quad \text { free }\right) \quad \forall t, n^{A C} \in \mathcal{N}^{A C} \\
f_{t, \ell^{A C}}-\sum_{n^{A C} \in \mathcal{N}^{A C}} H_{n^{A C}, \ell^{A C}} d_{t, n^{A C}}=0 \quad\left(\gamma_{t, \ell^{A C}} \text { free }\right) \quad \forall t, \ell^{A C} \in \mathcal{L}^{A C} \\
0 \leq \mu_{t, \ell}^{-} \perp-f_{t, \ell}-K_{\ell} \leq 0 \quad \forall t, \ell \\
0 \leq \mu_{t, \ell}^{+} \perp f_{t, \ell}-K_{\ell} \leq 0 \quad \forall t, \ell
\end{gathered}
$$

\subsection{Market-Clearing Conditions}

We impose a mass-balance condition in the electricity market by equating the difference between sales and production with net imports at each node, where import is given by the product of the network incidence matrix and power flows, $-\sum_{\ell} A_{n, \ell} f_{t, \ell}$ as in Equation (18). The difference between shadow prices, $\tau_{t, n}$, is precisely the wheeling fee earned by the grid owner in (9) and paid by producers in (1).

$$
N_{t}\left(\sum_{i} s_{t, i, n}-\sum_{i} x_{t, i, n}\right)=N_{t}\left(-\sum_{\ell} A_{n, \ell} f_{t, \ell}\right) \quad\left(\tau_{t, n} \text { free }\right) \quad \forall t, n
$$

\section{5. $M C P$}

The MCP is given by (5)-(8), (13a)-(17), and (18). It is a square system of ten blocks of equations and ten blocks of variables $\left\{\gamma_{t, \ell}, \theta_{t, i}, \tau_{t, n}, d_{t, n}, f_{t, \ell}, \lambda_{t, i, n}, \mu_{t, \ell}^{-}, \mu_{t, \ell}^{+}, s_{t, i, n}\right.$, and $\left.x_{t, i, n}\right\}$. The "squareness" of the problem is necessary for finding a solution computationally by using MCP solvers (Hobbs, 2001). The solution is a set of prices, quantities, flows, and consumption resulting from satisfying each agent's KKT conditions for profit maximisation while clearing the electricity market. This solution represents the Nash equilibrium where 
none of the players has the incentive to change its decisions unilaterally (Hobbs, 2001).

\section{Data Implementation, Calibration, and Results}

\subsection{Data and Assumptions}

We assess the extent of carbon leakage in the thirteen SEE-REM countries by using a 22node network with a high-voltage (HV) grid. We model only thermal and nuclear power units that are described by their marginal costs of production and $\mathrm{CO}_{2}$ emission intensities. Our analysis focuses on one year with four representative time blocks per month. Next, we describe the SEE-REM and provide a detailed description of how we obtained and implemented data for our numerical example of SEE-REM.

\subsubsection{South-East Europe Regional Electricity Market}

Countries in SEE-REM are chosen based on their association with the Energy Community ${ }^{8}$ and are: Albania $\left(\mathrm{AL}-n_{19}\right)$, Bosnia and Herzegovina $\left(\mathrm{BH}-n_{14}\right)$, Bulgaria $\left(\mathrm{BG}-n_{21}\right)$, Croatia $\left(\mathrm{HR}-n_{13}\right)$, Former Yugoslav Republic of Macedonia $\left(\mathrm{MK}-n_{17}\right)$, Greece $\left(\mathrm{GR}-n_{18}\right)$, Hungary $\left(\mathrm{HU}-n_{20}\right)$, Italy $\left(\mathrm{IT}-\left(n_{1}-n_{11}\right)\right)$, United Nations Interim Administration Mission in Kosovo $\left(\mathrm{XK}-n_{15}\right)$, Montenegro $\left(\mathrm{ME}-n_{16}\right)$, Republic of Serbia $\left(\mathrm{RS}-n_{15}\right)$, Romania $\left(\mathrm{RO}-n_{22}\right)$, and Slovenia $\left(\mathrm{SI}-n_{12}\right)$. As of 2013, seven of these countries are EU members and are, thus, subject to the EU ETS, viz., Bulgaria, Croatia, Greece, Hungary, Italy, Romania, and Slovenia.

In our numerical example, we apply a similar approach used in Green (2007) to simplify nodal representation of SEE-REM based on a 22-node network (see Figure 1). Each country is modelled by only one node with the exception of Serbia, Kosovo, and Italy. Serbia and Kosovo are jointly modelled as one node only because of lack of data in relation to the transmission capacities with Kosovo. Italy is modelled by 11 nodes representing existing 11 pricing zones. ${ }^{9}$

\footnotetext{
${ }^{8}$ The Energy Community is an international organisation for energy policy that was established by nine countries ("contracting parties") from the South-East European and Black Sea regions with the objective of integrating the contracting parties into the EU internal energy market. The Energy Community was established in 2005 by signing the "Treaty Establishing Energy Community" (Energy Community, 2005), when none of the contracting parties was part of the EU.

${ }^{9}$ Other countries use either uniform or tariff pricing (EBRD, 2010).
} 
Therefore, for the purpose of using the DC load flow to model flows, we calculate the nodal network transfer matrix based on Schweppe et al. (1988).

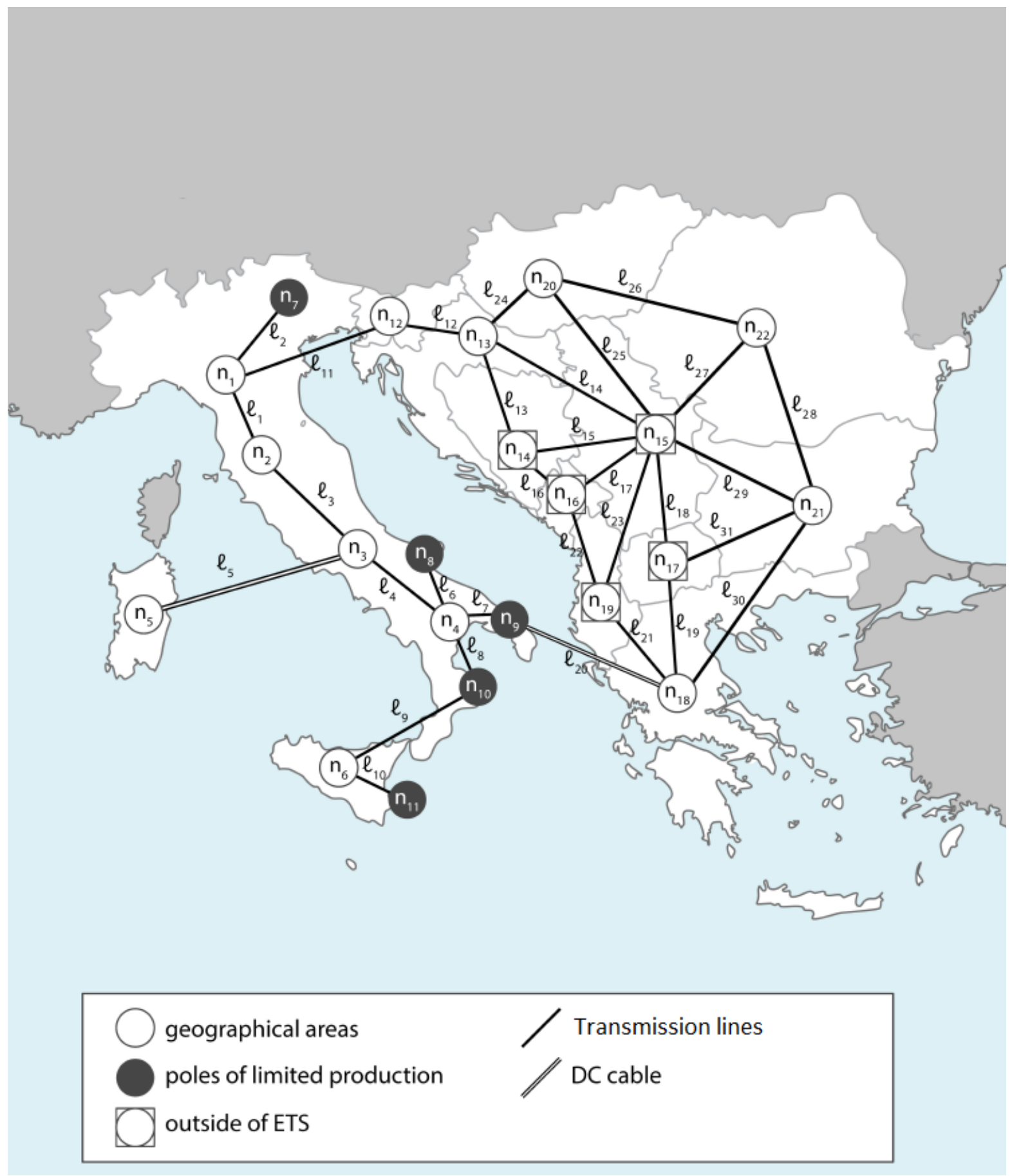

Figure 1: SEE-REM nodal representation 


\subsubsection{Line-Specific Data}

In relation to the network, we have one line between every pair of nodes. Limits of power flows on lines are given by the Net Transfer Capacities (NTCs), which are divided between winter values and summer values and are published by the European Network of Transmission System Operators for Electricity (ENTSO-E) in ENTSO-E (2011) and ENTSO-E (2012), respectively. The limits of power flows on the lines within Italy are obtained from the Italian TSO, Terna (Terna, 2013b). Note that NTCs are limits on commercial flows rather than actual thermal limits of the lines; however, we use NTCs as an approximation due to lack of actual data. Moreover, we distinguish between AC and DC lines and use the DC load-flow approximation to model the flows. Further discussion on both NTCs and DC load flow can be found in Appendix C.1.

\subsubsection{Node-Specific Capacities}

Thermal units are divided into six different technologies based on type of fuel and/or type of turbine, viz., coal, lignite, natural gas-steam turbine, natural gas-combined cycle (CCGT), fuel oil, and mixed fuels. With the exception of distinguishing between types of units fired by natural gas, ENTSO-E uses the same categories and publishes generation capacities per category per country on a yearly basis (ENTSO-E, 2013). In order to understand better the mixed fuels category, we use more detailed production data (see Appendix C.2.)

The differences between technologies are reflected in their marginal costs of production and $\mathrm{CO}_{2}$ emissions intensities (Table C-6), which are calculated from emissions factors (EU, 2012). We assume that mixed fuels are steam-turbine units that can be fired by both natural gas and fuel oil, and, thus, their emissions are given by the combination of emissions of natural gas and fuel oil. By contrast, for CCGT emissions, we assume that these are $20 \%$ lower than natural gas-steam turbine emissions because of the increased efficiency of power production of the CCGT (52\%-60\%) compared to the natural gas-steam turbine (35\%-42\%) (IEA, 2010). 


\subsubsection{Nodal Demand}

In order to represent the linear inverse demand function for each node, we estimate the coefficients of the function from reference demand, reference price, load curve, and reference elasticity as described in Appendix B. Because we are modelling only nuclear and thermal power units, to estimate reference demand, we start from consumption net of import/export, renewables, and hydropower units' production (Bushnell and Chen, 2012), which leaves us with residual consumption. The load curve serves the purpose of adding some variation to the average hourly demand. The process of obtaining residual demand from residual consumption and calculating the load curve is explained in detail in Appendix C.3.

Reference prices are obtained by running a cost-minimisation linear program with fixed demand where nodal electricity prices are given by dual variables on energy mass-balance constraints. These prices are then fed into the $\mathrm{MCP}$ with the price-responsive inverse demand function. The elasticity is assumed to be -0.25 for the whole system, which is consistent with that used in the literature (Egerer et al., 2014; Dietrich et al., 2005; Weigt, 2006).

\subsection{Scenario Description}

For the purpose of analysing carbon leakage and market outcomes in SEE-REM under the $\mathrm{CO}_{2}$ reduction targets (e.g., EU 20-20-20) and different levels of hydropower production, we propose three sets of scenarios where each set has a baseline scenario. The three baseline scenarios are defined by the level of hydropower production as listed in Table 1. In addition, we vary the price of $\mathrm{CO}_{2}$ allowances $(0,10,20,30,40,50 \mathrm{in} € / \mathrm{t}$, where "t" is an abbreviation

for metric tons) for each level of hydropower production. We have 18 scenarios in total, of which three are baseline scenarios with $\mathrm{CO}_{2}$ prices of zero, and 15 scenarios with prices of $\mathrm{CO}_{2}$ allowances from $€ 10-50 / \mathrm{MWh}$. 


\begin{tabular}{ll}
\hline Scenario & Description \\
\hline Baseline & Used for calibration based on data from 2013 \\
Base-dry & Base year for hydropower production based on 2011 data \\
Base-wet & Base year for hydropower production based on 2010 data \\
\hline
\end{tabular}

Table 1: Scenario and description

\subsection{Calibration}

We analyse the calibration of our baseline scenario considering three quantities: generation per fuel type, emissions, and electricity prices. Generally, production per fuel type is overestimated for cheaper fuels and underestimated for more expensive fuels; however, total production in SEE-REM is overestimated by $9.55 \%$. As a consequence of overestimation of production, emissions in SEE-REM are also overestimated by $4.99 \%$. Price patterns across nodes are well captured; however, prices in the model are lower at nodes that in reality have higher production from expensive fuels.

\subsubsection{Generation Fuel Mix}

We divide the analysis of production by type of fuel into ETS and non-ETS areas (Figures 2 and 3, respectively). In the ETS area, production from cheaper sources such as coal, natural gas, nuclear, and lignite is overestimated by $22.10 \%, 12.46 \%, 11.02 \%$, and $14.56 \%$, respectively. Production in the non-ETS area is mostly given by lignite-fired power plants, and it is overestimated by $32.07 \%$. Production from relatively more expensive fuels like mixed fuels and fuel oil in both ETS and non-ETS is underestimated. Because of this, the overall production in the ETS area is overestimated by $6.91 \%$ and in the non-ETS area by $29.66 \%$. Finally, the overall production in the SEE-REM area is overestimated by $9.55 \%$, which is of less concern for our study because we aim to capture the price variation among the nodes.

We believe that there are two explanations for the discrepancies found in generation from more expensive fuels. First, the model chooses the optimal solution for generating from each 


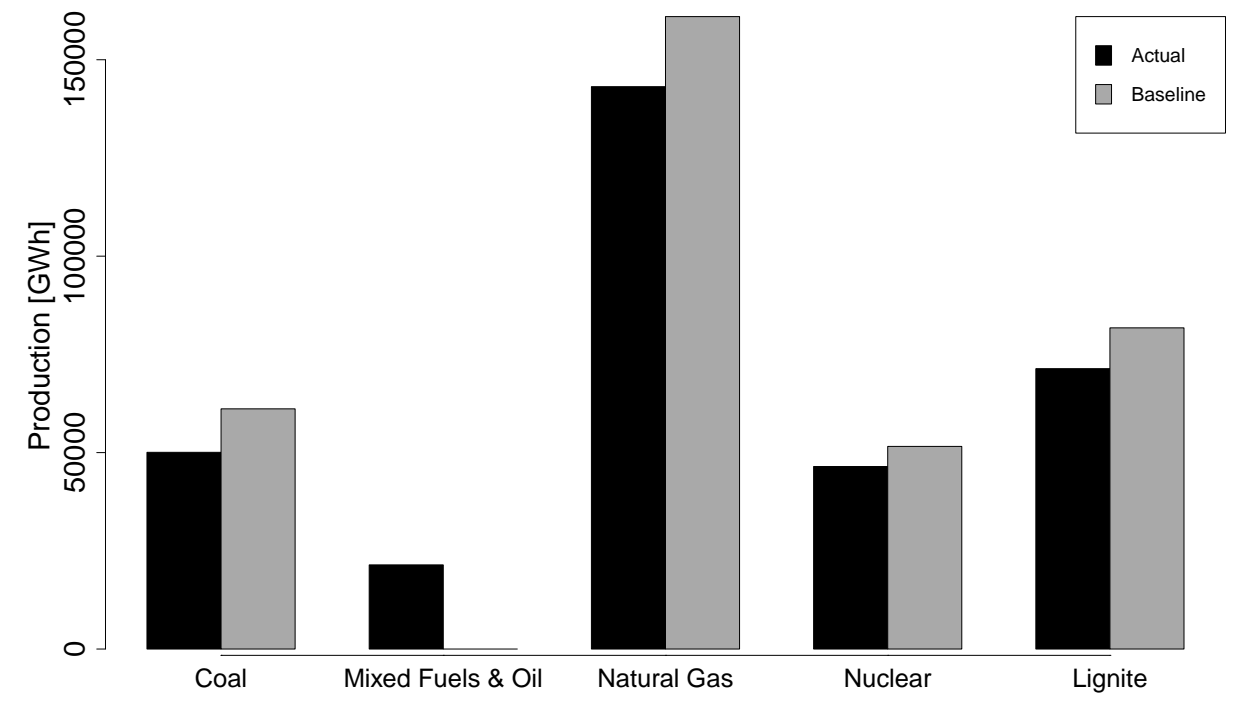

Figure 2: Generation per type of fuel in the ETS area

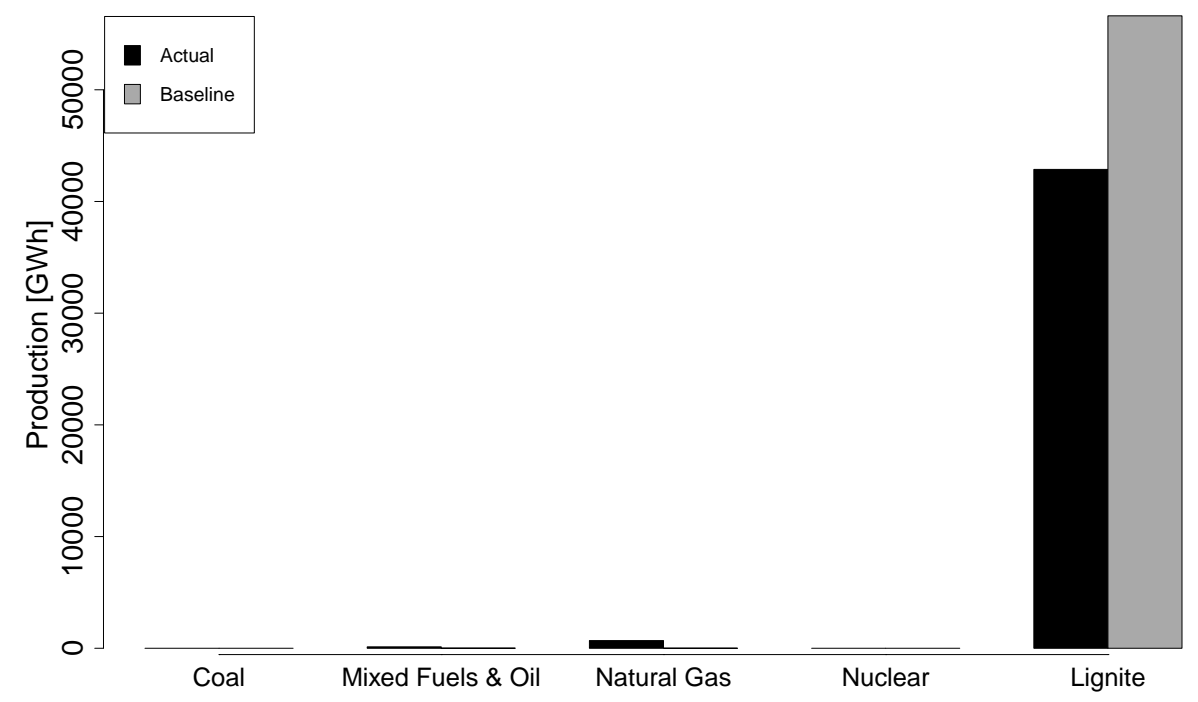

Figure 3: Generation per type of fuel in the non-ETS area 
fuel based on given constraints; however, in reality, the choice of operating generating units might not always be efficient (e.g., less-efficient units based on fuel oil, for example, might be required to deal with short-term situations, like ensuring network security). Second, the model does not include any dynamic power plant constraints (e.g., ramp-up constraints), the absence of which might mean larger cost differences between generating technologies in the model than in reality for certain time periods (e.g., ramping hours). Consequently, technologies using more expensive fuels might not become viable options. Although estimation of production per fuel type varies based on fuel type, overall SEE-REM production is overestimated by $9.55 \%$, which, considering that we do not take into account ramping constraints, we believe to be a reasonable calibration.

\subsubsection{Emissions}

Emissions in the ETS and non-ETS areas (Figure 4) are underestimated by $0.24 \%$ and overestimated by $29.95 \%$, respectively, with the total SEE-REM emissions being overestimated by $4.99 \%$. The overestimation of emissions is related to the overestimation of production. Although it is expected that emissions are overestimated given that generation is overestimated, the emissions are calibrated more closely than generation. The reason for this discrepancy is related to the fact that the actual generation mix contains more polluting fuels (such as fuel oil) than the modelled one.

\subsubsection{Electricity Prices}

We compare average annual wholesale electricity prices for six pricing zones in Italy, Slovenia, Greece, Hungary, and Romania. Actual and modelled prices are shown in Figure 5. Because we are modelling residual demand, the actual prices need to be adjusted for the purpose of comparison such that point elasticity is preserved. A detailed explanation for obtaining adjusted prices is provided in Appendix C.4. The model seems to capture well the differences in prices between the nodes as the pattern is reproduced quite closely. There are a few exceptions, viz., IT6 and GR, where more expensive fuels, including oil and mixed fuels, 


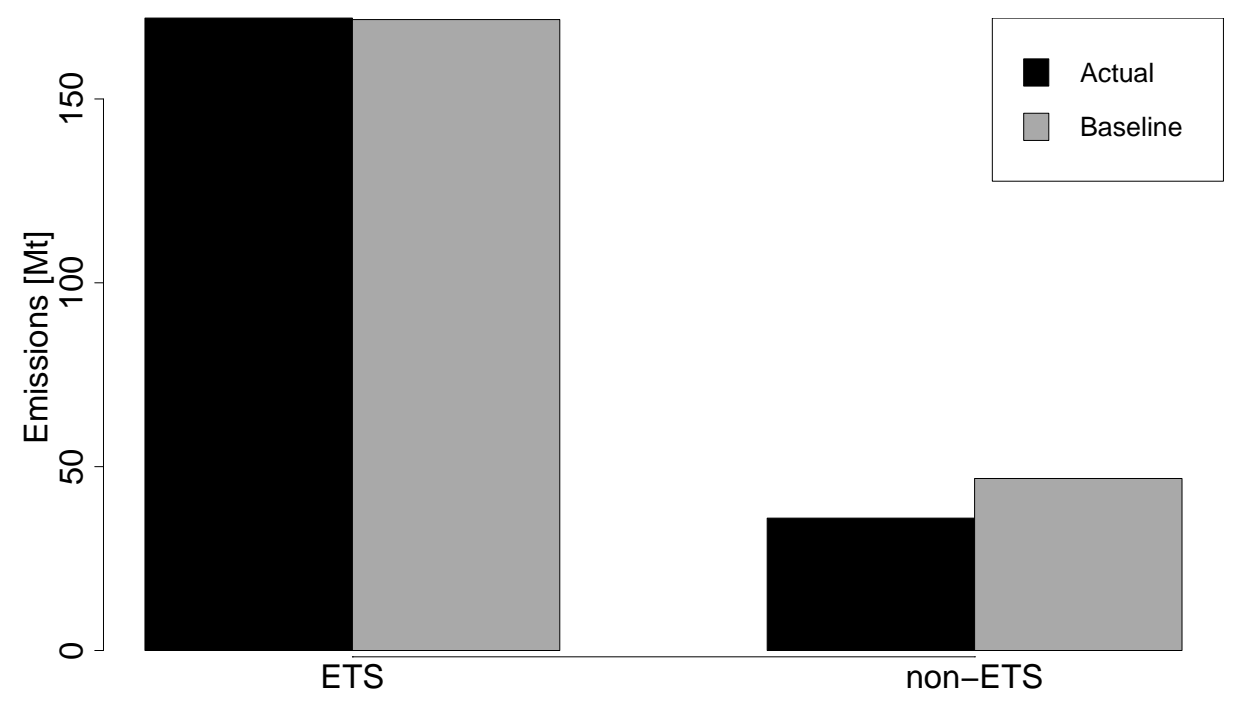

Figure 4: Emissions in the ETS and non-ETS areas

are used more frequently in reality. Because our model does not capture the generation from these expensive fuels, it does not fully capture electricity prices at these nodes either.

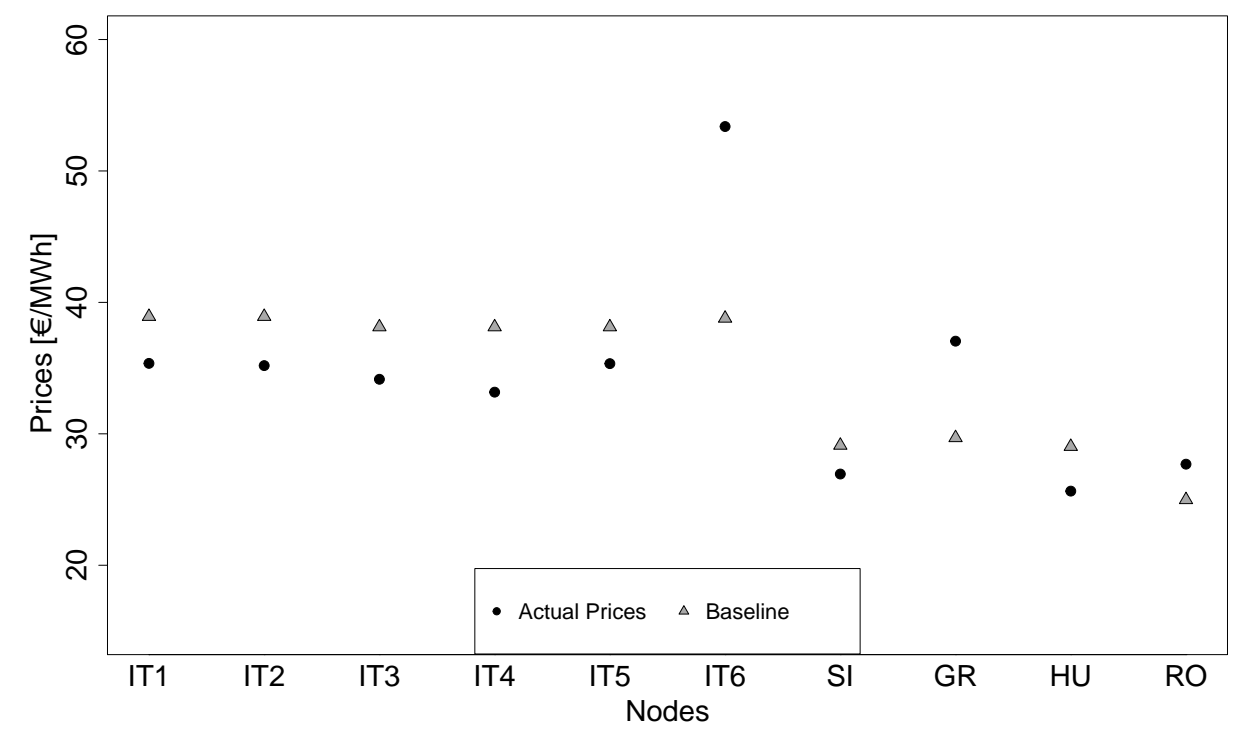

Figure 5: Electricity prices in Italy, Slovenia, Greece, Hungary, and Romania in 2013

\subsection{Carbon Leakage Measures}

In this paper, we define carbon leakage as the increase in emissions in the non-regulated area as a result of imposing the cap on emissions in the regulated area. This definition 
is consistent with that in Chen (2009). In order to measure carbon leakage, Chen (2009) considers two metrics, leakage and relative leakage (RL). The author defines leakage as the change in emissions in the non-regulated area before and after the introduction of the cap, and this is given by $\Delta C O_{2}^{N}=Z_{A}^{N}-Z_{B}^{N}$, where $Z$ are the emissions with the subscript B (A) indicating the state before (after) the cap and superscript N (ETS) indicates the non-ETS (ETS) area of the regional market. Furthermore, the author defines RL as the percentage of leakage in terms of the emissions reduction in the regulated area. Relative leakage is given in Equation (19).

$$
R L=\left|\frac{\Delta C O_{2}^{N}}{\Delta C O_{2}^{E T S}}\right| \times 100 \%
$$

RL measures the impact of carbon leakage relative to the reduction in the regulated area. For example, if RL is equal to $50 \%$, then it means that the emissions in the non-regulated area increase by $50 \%$ of the reduction achieved in the regulated area. Because $\triangle C O_{2}^{E T S}$ $\left(\Delta C O_{2}^{N}\right)$ is the product of the $\Delta$ output ${ }^{E T S}\left(\Delta o u t p u t^{N}\right)$ and the emissions rate, a one unit increase in output with non-zero emissions rate in the non-regulated area means that RL will be greater than zero. If $\Delta C O_{2}^{N}>\Delta C O_{2}^{E T S}$, then RL will be greater than $100 \%$. However, as Chen (2009) points out, whether $\Delta C O_{2}^{N}>\Delta C O_{2}^{E T S}$ depends on the circumstances, e.g., the generation mix for a certain load level, of the particular market under consideration.

Although RL is an intuitive measure of carbon leakage, it is sensitive to emissions reduction in the regulated area. In the specific case of SEE-REM, this indicates a steady decrease in relative leakage with a higher allowance price because the generating capacity in the non-ETS area is relatively small compared to the whole SEE-REM generating capacity and demand. This means that carbon leakage in SEE-REM is limited by the installed generating capacity in the non-ETS area. However, this also suggests that the RL measure will not be able to detect more subtle effects, such as demand response in the non-ETS area, that might occur and are not related to reduction of emissions in the ETS area. For this purpose, we introduce a more robust measure for carbon leakage called reduction reversal (RR).

RR measures the difference between total emissions after the cap and total emissions 
expected to be achieved under the no leakage assumption relative to the total emissions before the cap. Under the assumption of "no leakage", we expect the emissions of $\mathrm{N}$ to remain the same while at the same time we expect a reduction in the ETS; therefore, the total expected emissions are given by $\left(Z_{A}^{E T S}+Z_{B}^{N}\right)$. The $\mathrm{RR}$ is given in Equation (20), and it can trivially be reduced to Equation (21). As such, RR measures the reversal of emissions reduction achieved in the ETS area under the cap.

$$
\begin{aligned}
& R R=\left(\frac{\left(Z_{A}^{E T S}+Z_{A}^{N}\right)-\left(Z_{A}^{E T S}+Z_{B}^{N}\right)}{Z_{B}^{T O T}}\right) \times 100 \% \\
& R R=\left(\frac{\Delta C O_{2}^{N}}{Z_{B}^{T O T}}\right) \times 100 \%
\end{aligned}
$$

A drawback of RR lies in the total expected emissions assumption because the emissions reduction that has been achieved in the ETS area under the cap is partly a result of the ability to import from the non-ETS area. This means that the reduction of emissions in the ETS examined in isolation of the non-ETS might not be achieved, ceteris paribus. As such, RR is not as useful as RL for quantifying carbon leakage. However, because RR is not sensitive to ETS reduction of emissions, it has the ability to pick up subtler effects, such as the reduction of leakage due to demand response in the non-ETS area that might influence carbon leakage. For the sake of completeness of examination of carbon leakage, we report and comment on both RR and RL.

\subsection{Results Analysis and Discussion}

In this section, we analyse the results and divide our analysis of $\mathrm{CO}_{2}$ reduction into demand response, fuel switching, and carbon leakage. Our analysis is divided as such because we are focusing on the short-term impact of C\&T, i.e., before any adjustments to capacity and retrofitting can be made. Specifically, in our model, we assume that renewables are generating at their maximum feasible levels for the considered period of time. However, in the longer term, $\mathrm{CO}_{2}$ emissions can also be reduced through new renewable generation. Nevertheless, 
the effect of increases in renewables on the magnitude of emission leakage is ambiguous, ${ }^{10}$ but this is beyond the scope of our paper. We have three central findings: carbon leakage may be limited by demand response to higher electricity prices in non-ETS countries, greater hydropower availability may result in higher ETS emissions compared to the baseline, and, depending on the price of allowances, $6.3 \%$ to $40.5 \%$ of the emissions reduction achieved in the ETS part of SEE-REM could be displaced to the non-ETS part.

In Table 3, we present main results related to emissions and carbon leakage in different scenarios. We have three types of water years, viz., wet, dry, and normal, with six levels of $\mathrm{CO}_{2}$ allowance prices $(€ 0-50 / \mathrm{t})$. Each type of water year has a base scenario where the price of allowances is equal to $€ 0 / \mathrm{MWh}$ against which we compare emissions reduction/increase and carbon leakage.

\subsubsection{Demand Response}

Introduction of allowance prices translates into a higher cost of production for the producers in the ETS area, thereby leading to higher electricity prices. Higher electricity prices in the ETS area suppress power quantity demanded and induce increased imports from the non-ETS area. The latter is due to the fact that higher ETS-region electricity prices offer economic incentives for non-ETS producers to increase their exports while, at the same time, driving up non-ETS prices. The increase in domestic prices in the non-ETS area driven by higher allowance prices might eventually curb non-ETS consumption (particularly evident in the wet-year scenarios), which then offsets the emissions caused by higher exports from the non-ETS area, thereby resulting in a decrease of leakage as measured by RR. In summary, the decrease in carbon leakage is given by non-ETS consumers' response to higher electricity prices due to the price-responsive demand assumption. In fact, the decrease in carbon leakage does not occur in the case of fixed demand (Table 4). With fixed demand, the only recourse

\footnotetext{
${ }^{10}$ On the one hand, if the cost of newly introduced renewables is lower than those units that ramp up their outputs in non-ETS countries due to emissions trading, then leakage should be mitigated. On the other hand, even if this is the case, then other ramping units might be needed due to intermittence of renewables (Rintamäki et al., 2016), and, consequently, the impact of renewables on emissions leakage might be limited.
} 
to a higher $\mathrm{CO}_{2}$ price is fuel switching. Consequently, although modelled emissions are higher in Table 4 compared to those in Table 3, carbon leakage as measured by RR monotonically increases with the $\mathrm{CO}_{2}$ price.

\subsubsection{Fuel Switching}

As for the decomposition of $\mathrm{CO}_{2}$ reduction, the inclusion of allowance prices changes the merit order of supply, thereby leading to fuel switching. In Table 2, we examine the three most frequently used technologies and how their costs vary and compare with price of allowances. Figure 6 indicates that the biggest incremental drops in emissions occur at $€ 10 / \mathrm{t}$ and $€ 40 / \mathrm{t}$. The former is expected because of the introduction of the allowance price, and the latter occurs when the price of natural gas becomes the cheapest among the three examined fuels. Although coal becomes cheaper than lignite at $€ 20 / t$, the cost difference is not sufficiently high to cause a major decrease in emissions.

\begin{tabular}{cccccc}
\multicolumn{6}{c}{ Price of ETS allowances [€/t] } \\
\hline 0 & 10 & 20 & 30 & 40 & 50 \\
\hline Lignite & Lignite & Coal & Coal & Nat. gas & Nat. gas \\
Coal & Coal & Lignite & Lignite & Coal & Coal \\
Nat. gas & Nat. gas & Nat. gas & Nat. gas & Lignite & Lignite \\
\hline
\end{tabular}

Table 2: Relation of fuel costs with the cheapest fuel at the top and the most expensive one at the bottom 


\begin{tabular}{|c|c|c|c|c|c|c|c|c|c|c|c|c|c|c|}
\hline \multirow{2}{*}{ 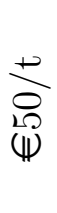 } & 乙 & & $\begin{array}{l}2 \\
10 \\
10\end{array}$ & $\begin{array}{l}\stackrel{H}{H} \\
\text { î. }\end{array}$ & $\underset{n}{\infty}$ & $\stackrel{m}{=}$ & $\stackrel{\sim}{7}$ & $\stackrel{\Omega}{\longrightarrow}$ & \multirow{2}{*}{ 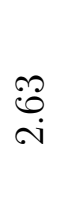 } & \multirow{2}{*}{$\begin{array}{l}0 \\
10 \\
i \\
\sim\end{array}$} & \multirow{2}{*}{$\begin{array}{l}8 \\
\text { is }\end{array}$} & \multirow{2}{*}{$\begin{array}{l}\infty \\
\infty \\
0\end{array}$} & \multirow{2}{*}{$\begin{array}{l}\stackrel{9}{0} \\
0\end{array}$} & \multirow{2}{*}{$\vec{\sigma}$} \\
\hline & 坃 & & $\stackrel{8}{\varrho}$ & $\infty$ & $\sigma^{\prime}$ & $\underset{i}{\infty}$ & iิ & $\underset{1}{\stackrel{P}{+}}$ & & & & & & \\
\hline \multirow{2}{*}{ 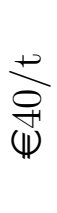 } & 乙 & & $\begin{array}{l}4 \\
20 \\
10\end{array}$ & $\begin{array}{l}\not{H} \\
\text { กิ่ }\end{array}$ & $\frac{9}{10}$ & $\stackrel{m}{=}$ & $\stackrel{\sim}{\simeq}$ & $\stackrel{\Omega}{(-1}$ & \multirow{2}{*}{ 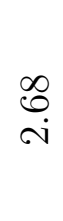 } & \multirow{2}{*}{ 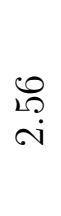 } & \multirow{2}{*}{$\begin{array}{l}10 \\
0 \\
0\end{array}$} & \multirow{2}{*}{ 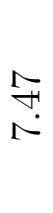 } & \multirow{2}{*}{$\begin{array}{l}\frac{10}{1} \\
0\end{array}$} & \multirow{2}{*}{$\begin{array}{l}\infty \\
\infty \\
0 .\end{array}$} \\
\hline & 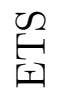 & & ڤo & $\stackrel{\infty}{ }$ & $\underset{-1}{\stackrel{-}{0}}$ & $\stackrel{2 \rho}{\rightarrow}$ & $\underset{+}{\infty}$ & 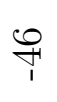 & & & & & & \\
\hline+ & 乙 & & $\underset{10}{9}$ & $\begin{array}{l}\text { No } \\
\text { กิ่ }\end{array}$ & $\frac{9}{210}$ & $\stackrel{\sim}{\mp}$ & $\stackrel{\sim}{\tau}$ & $\stackrel{\Omega}{=}$ & \multirow{2}{*}{ 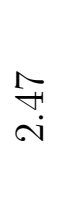 } & \multirow{2}{*}{$\begin{array}{l}\stackrel{N}{\forall} \\
\stackrel{\sim}{*}\end{array}$} & \multirow{2}{*}{ نَ } & \multirow{2}{*}{$\begin{array}{l}\stackrel{\Omega}{\sim} \\
\stackrel{+}{+}\end{array}$} & \multirow{2}{*}{ 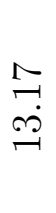 } & \multirow{2}{*}{$\begin{array}{l}\infty \\
\infty \\
\infty\end{array}$} \\
\hline $\mathbb{\Psi}$ & $\begin{array}{l}\sigma_{1} \\
\qquad\end{array}$ & & î & $\vec{m}$ & $\underset{\sim}{\stackrel{9}{\sim}}$ & $\underset{\sim}{\stackrel{N}{*}}$ & $\underset{\sim}{\sim}$ & $\stackrel{\vec{\sim}}{\sim}$ & & & & & & \\
\hline \multirow{2}{*}{ 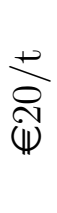 } & Z & & $\begin{array}{l}0 \\
10 \\
10\end{array}$ & $\begin{array}{l}\text { ?. } \\
\text { ĩ }\end{array}$ & $\frac{9}{10}$ & $\stackrel{\sim}{\sim}$ & $\stackrel{\sim}{\sim}$ & $\stackrel{\Omega}{(-1}$ & \multirow{2}{*}{$\begin{array}{l}\text { in } \\
\text { in }\end{array}$} & \multirow{2}{*}{$\begin{array}{l}\overrightarrow{20} \\
\stackrel{i}{1}\end{array}$} & \multirow{2}{*}{$\begin{array}{l}10 \\
0 \\
\text { is }\end{array}$} & \multirow{2}{*}{$\begin{array}{l}\infty \\
0 \\
\infty \\
\infty\end{array}$} & \multirow{2}{*}{$\begin{array}{l}\stackrel{+}{N} \\
\stackrel{N}{C}\end{array}$} & \multirow{2}{*}{ مֶ } \\
\hline & $\begin{array}{l}\mathcal{E}_{1} \\
\underline{I}\end{array}$ & & $\underset{7}{0}$ & 李 & $\stackrel{\sqrt{20}}{-1}$ & $\stackrel{0}{\underset{1}{1}}$ & $\frac{\infty}{1}$ & $\frac{\infty}{1}$ & & & & & & \\
\hline \multirow{2}{*}{ 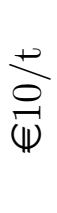 } & 乙 & & $\stackrel{9}{+\infty}$ & $\begin{array}{l}\stackrel{N}{ } \\
\text { î }\end{array}$ & 范 & $\stackrel{\sim}{\sim}$ & $\stackrel{\sim}{-1}$ & $\stackrel{\Omega}{(-1}$ & \multirow{2}{*}{$\begin{array}{l}\stackrel{N}{\not} \\
\stackrel{\sim}{*}\end{array}$} & \multirow{2}{*}{$\begin{array}{l}\stackrel{N}{\forall} \\
\stackrel{\sim}{*}\end{array}$} & \multirow{2}{*}{$\begin{array}{l}0 \\
10 \\
\infty\end{array}$} & \multirow{2}{*}{ 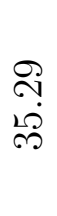 } & \multirow{2}{*}{$\begin{array}{l}\stackrel{8}{8} \\
\dot{\infty} \\
\text {. }\end{array}$} & \multirow{2}{*}{$\stackrel{0}{\circ}$} \\
\hline & 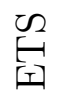 & & $\stackrel{N}{\stackrel{N}{二}}$ & $\stackrel{10}{10}$ & రై & $\sigma_{1}$ & 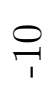 & ${ }_{7}$ & & & & & & \\
\hline \multirow{2}{*}{ 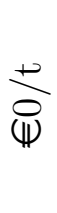 } & Z & ח & $\begin{array}{l}\infty \\
\stackrel{+}{\not}\end{array}$ & $\begin{array}{l}\infty \\
\stackrel{0}{0} \\
\stackrel{+}{0}\end{array}$ & 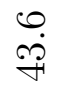 & 0 & 0 & 0 & 凤 & 尺 & $\oslash$ & 0 & 0 & ○ \\
\hline & $\frac{\sigma_{1}}{H}$ & $\stackrel{N}{\tau}$ & $\stackrel{\vec{\sigma}}{\longrightarrow}$ & $\stackrel{\mathcal{N}}{\sim}$ & $\underset{-1}{\infty}$ & 0 & 0 & 0 & $\dot{0}$ & $\dot{0}$ & $\dot{0}$ & $\dot{0}$ & $\dot{0}$ & $\dot{0}$ \\
\hline 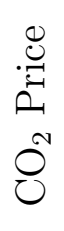 & 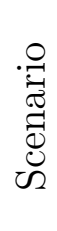 & 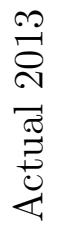 & $\begin{array}{l}\vec{Z} \\
0 \\
0 \\
\tilde{ే} \\
\tilde{D}\end{array}$ & 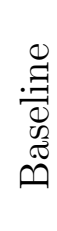 & $\begin{array}{l}\vec{D} \\
\vdots \\
0 \\
\tilde{W} \\
\tilde{D} \\
\tilde{D}\end{array}$ & $\begin{array}{l}\vec{Z} \\
0 \\
0 \\
\tilde{\tilde{Z}} \\
\tilde{\tilde{\theta}}\end{array}$ & 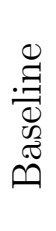 & 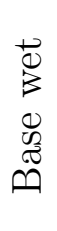 & $\begin{array}{l}\vec{Z} \\
\vec{\theta} \\
0 \\
\tilde{D} \\
\tilde{\tilde{n}}\end{array}$ & 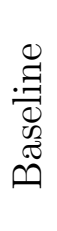 & 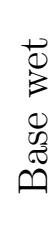 & $\begin{array}{l}\vec{Z} \\
0 \\
0 \\
\tilde{E} \\
\tilde{\theta}\end{array}$ & 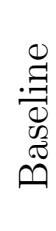 & $\begin{array}{l}\overrightarrow{0} \\
\vec{\beta} \\
0 \\
\tilde{W} \\
\tilde{D}\end{array}$ \\
\hline & & & & & & & 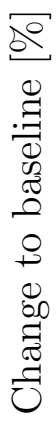 & & & $\frac{\widetilde{a}}{\stackrel{a}{a}}$ & & & $\begin{array}{l}0 \\
0 \\
0\end{array}$ & \\
\hline
\end{tabular}

Table 3: Main results related to emissions and carbon leakage 


\begin{tabular}{|c|c|c|c|c|c|c|c|c|c|c|c|c|c|c|}
\hline \multirow{2}{*}{ 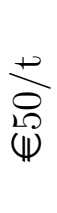 } & 乙 & & 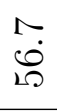 & $\frac{0}{10}$ & $\begin{array}{l}\text { Oे } \\
\text { in }\end{array}$ & $\stackrel{0}{\varrho}$ & $\stackrel{\leftrightarrow}{\leftrightarrow}$ & $\stackrel{L}{\sim}$ & \multirow{2}{*}{$\begin{array}{l}\vec{\sim} \\
\text { ஸे }\end{array}$} & \multirow{2}{*}{$\begin{array}{l}\vec{\forall} \\
\dot{\nabla}\end{array}$} & \multirow{2}{*}{$\begin{array}{l}0 \\
\mathscr{\nabla} \\
\dot{\nabla}\end{array}$} & \multirow{2}{*}{ 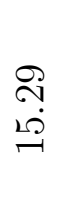 } & \multirow{2}{*}{$\begin{array}{l}\stackrel{R}{1} \\
\infty \\
\rightarrow-1\end{array}$} & \multirow{2}{*}{$\stackrel{0}{\stackrel{0}{N}}$} \\
\hline & $\underset{\text { E }}{E}$ & & $\stackrel{\mathscr{P}}{\rightarrow}$ & $\stackrel{\overbrace{}}{\stackrel{\overbrace{}}{-}}$ & ஸै & $\overbrace{1}$ & $\vec{p}$ & 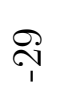 & & & & & & \\
\hline \multirow{2}{*}{ 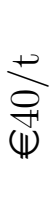 } & 乙 & & $\begin{array}{l}1 \\
6 \\
0\end{array}$ & $\begin{array}{l}0 \\
\text { in } \\
\text { in }\end{array}$ & סُ & $\stackrel{0}{-1}$ & $\stackrel{\sim}{\sim}$ & $\stackrel{\stackrel{2}{N}}{N}$ & \multirow{2}{*}{$\begin{array}{l}\vec{\sim} \\
\text { is }\end{array}$} & \multirow{2}{*}{ مُ } & \multirow{2}{*}{$\underset{\vec{\nabla}}{\vec{b}}$} & \multirow{2}{*}{ 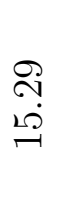 } & \multirow{2}{*}{$\begin{array}{l}\text { iv } \\
\text { if } \\
\infty \\
-1\end{array}$} & \multirow{2}{*}{$\stackrel{\infty}{\infty}$} \\
\hline & 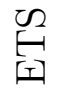 & & $\stackrel{\mathscr{P}}{\rightleftarrows}$ & $\stackrel{\overbrace{}}{\stackrel{(}{-}}$ & ๓े & 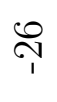 & $\vec{P}$ & $\stackrel{\text { ণ }}{\text { I }}$ & & & & & & \\
\hline+ & 乙 & & $\begin{array}{l}N \\
10 \\
10\end{array}$ & $\begin{array}{l}\text { 소 } \\
\text { i่ }\end{array}$ & $\begin{array}{l}\text { Lo } \\
\text { i่ }\end{array}$ & $\stackrel{\infty}{=}$ & 尺ి & $\stackrel{\leftrightarrow}{\sim}$ & \multirow{2}{*}{$\begin{array}{l}\stackrel{2}{0} \\
\stackrel{1}{0}\end{array}$} & \multirow{2}{*}{$\underset{+}{\stackrel{\vec{H}}{ }}$} & \multirow{2}{*}{$\begin{array}{l}\stackrel{10}{\circ} \\
\stackrel{2}{+}\end{array}$} & \multirow{2}{*}{$\begin{array}{l}\stackrel{8}{0} \\
\stackrel{0}{0}\end{array}$} & \multirow{2}{*}{$\begin{array}{l}\stackrel{8}{0} \\
\stackrel{\infty}{\infty}\end{array}$} & \multirow{2}{*}{ 물 } \\
\hline$(\Psi)$ & $\begin{array}{l}\sigma_{1} \\
\qquad\end{array}$ & & $\stackrel{10}{\infty}$ & $\stackrel{\mathscr{B}}{\mathscr{0}}$ & $\stackrel{N}{\stackrel{N}{-}}$ & $v_{p}$ & $\varphi_{1}$ & $\Gamma_{1}$ & & & & & & \\
\hline \multirow{2}{*}{ 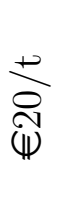 } & Z & & $\begin{array}{l}\text { Nִ } \\
\text { in } \\
20\end{array}$ & $\begin{array}{l}0 \\
\text { iv } \\
\text { î. }\end{array}$ & $\begin{array}{l}\text { H. } \\
\text { in }\end{array}$ & $\stackrel{m}{=}$ & ๑ి & $\stackrel{\Re}{\sim}$ & \multirow{2}{*}{ 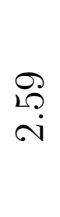 } & \multirow{2}{*}{ के } & \multirow{2}{*}{$\stackrel{\vec{n}}{\vec{H}}$} & \multirow{2}{*}{$\begin{array}{l}\stackrel{8}{0} \\
\stackrel{0}{1}\end{array}$} & \multirow{2}{*}{$\begin{array}{l}\mathscr{Q} \\
\stackrel{\rho}{1}\end{array}$} & \multirow{2}{*}{$\begin{array}{l}\infty \\
\stackrel{\infty}{\infty} \\
\stackrel{1}{N}\end{array}$} \\
\hline & 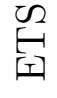 & & $\stackrel{10}{\infty}$ & $\stackrel{\mathscr{B}}{0}$ & 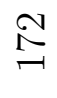 & $v_{i}$ & $\varphi_{1}$ & $\Gamma_{1}$ & & & & & & \\
\hline \multirow{2}{*}{ 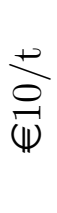 } & 乙 & & $\begin{array}{l}\infty \\
\dot{1} \\
20\end{array}$ & $\frac{9}{10}$ & $\frac{\Re}{i n}$ & $\stackrel{\sim}{\sim}$ & $\stackrel{\infty}{=}$ & $\stackrel{\curvearrowright}{\curvearrowright}$ & \multirow{2}{*}{ 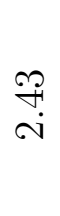 } & \multirow{2}{*}{$\begin{array}{l}\hat{0} \\
\text { is }\end{array}$} & \multirow{2}{*}{$\begin{array}{l}\infty \\
\infty \\
\infty \\
\infty\end{array}$} & \multirow{2}{*}{$\begin{array}{l}\stackrel{\curvearrowright}{\text { D }} \\
\dot{\infty}\end{array}$} & \multirow{2}{*}{$\begin{array}{l}8 \\
\stackrel{8}{8} \\
\stackrel{-}{\circ}\end{array}$} & \multirow{2}{*}{$\begin{array}{l}\hat{6} \\
\text { बं }\end{array}$} \\
\hline & 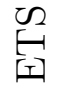 & & 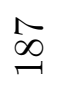 & ఠర & $\stackrel{0}{\stackrel{L}{L}}$ & $\underset{i}{+}$ & $L_{1}$ & $L_{i}$ & & & & & & \\
\hline \multirow{2}{*}{ 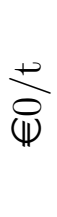 } & Z & ח & $\begin{array}{l}\stackrel{\rho}{\infty} \\
\stackrel{+}{0}\end{array}$ & $\stackrel{\leftrightarrow}{\stackrel{\rho}{\leftrightarrow}}$ & $\begin{array}{l}0 \\
\stackrel{\leftrightarrow}{\sim}\end{array}$ & 0 & 0 & 0 & 凤 & 凤 & 凤 & 0 & 0 & 0 \\
\hline & 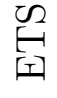 & $\stackrel{N}{C}$ & $\stackrel{\leftrightarrow}{\rightarrow}$ & $\stackrel{+}{\mathbb{L}}$ & $\stackrel{2 \infty}{\infty}$ & 0 & 0 & 0 & 0 & 0 & 0 & 0 & 0 & 0 \\
\hline 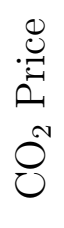 & 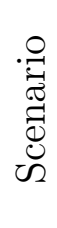 & 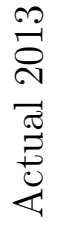 & $\begin{array}{l}\vec{Z} \\
0 \\
0 \\
\tilde{D} \\
\tilde{D}\end{array}$ & 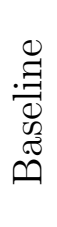 & $\begin{array}{l}\overrightarrow{0} \\
\vdots \\
0 \\
0 \\
\tilde{W} \\
\tilde{\omega}\end{array}$ & $\begin{array}{l}\vec{Z} \\
0 \\
0 \\
\tilde{\tilde{Z}} \\
\tilde{\tilde{\theta}}\end{array}$ & 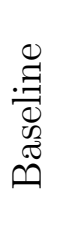 & $\begin{array}{l}\overrightarrow{0} \\
\vdots \\
0 \\
0 \\
\tilde{D} \\
\tilde{D}\end{array}$ & $\begin{array}{l}\vec{Z} \\
\vec{\theta} \\
0 \\
\tilde{D} \\
\tilde{\tilde{n}}\end{array}$ & 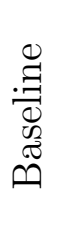 & $\begin{array}{l}\overrightarrow{0} \\
\vdots \\
0 \\
\tilde{W} \\
\tilde{D} \\
\tilde{D}\end{array}$ & $\begin{array}{l}\vec{\theta} \\
\vec{\theta} \\
0 \\
\tilde{D} \\
\tilde{\tilde{n}}\end{array}$ & 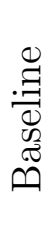 & $\begin{array}{l}\overrightarrow{0} \\
\vec{b} \\
0 \\
\tilde{W} \\
\tilde{\omega} \\
\oplus\end{array}$ \\
\hline & & & & & & & 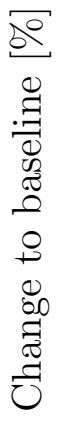 & & & $\frac{\widetilde{a}}{\stackrel{a}{a}}$ & & & $\begin{array}{l}\overparen{2} \\
\overrightarrow{2}\end{array}$ & \\
\hline
\end{tabular}

Table 4: Main results related to emissions and carbon leakage in the fixed-demand case 


\subsubsection{Emissions, Carbon Leakage, and Demand Response}

In relation to the interaction between $\mathrm{CO}_{2}$ allowances prices and levels of hydropower production, three observations are worth noting. First, ETS and non-ETS emissions are higher in the dry year compared to the baseline. Higher emissions in the dry year are expected because a larger proportion of demand is covered by conventional thermal generation due to unavailability of hydropower capacity.

Second, emissions in the SEE-REM ETS area are higher in wet-year scenarios. This is in contrast to our initial belief that high availability of non-polluting hydropower would lead to lower emissions under wet-year scenarios compared to the baseline. This is mainly because higher availability of cheap non-polluting hydropower lowers electricity prices, thereby inflating consumption and emissions. Although the rebound effect is mostly defined in the context of energy efficiency (Gillingham et al., 2016), the increase in electricity consumption and emissions in the ETS area in the case of higher hydropower availability can be viewed similarly.

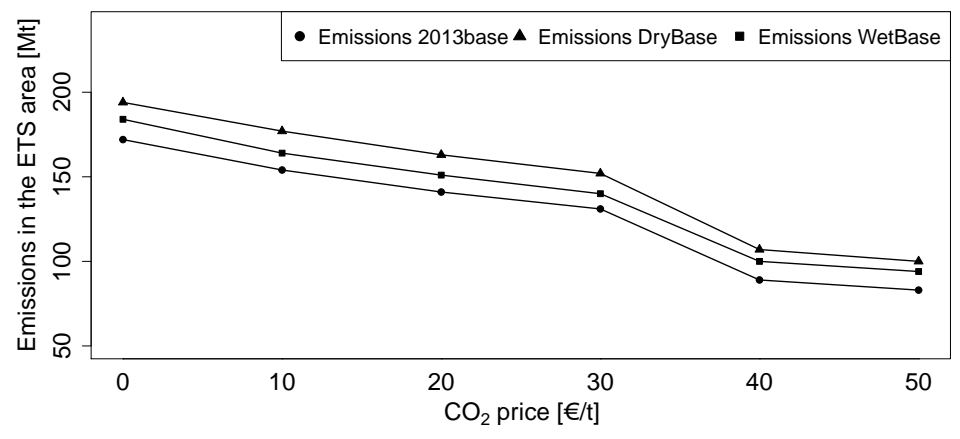

Figure 6: $\mathrm{CO}_{2}$ emissions in the ETS area

Third, higher $\mathrm{CO}_{2}$ allowance prices lead to consistently less leakage according to $\mathrm{RL}$ (Figure 8), which is not the case if we look at the RR measure where leakage varies depending on the price of allowances (Figure 9). According to RL, for an allowance price of $€ 10 / t$, approximately $40.5 \%$ of the reduction achieved under the ETS is displaced to the non-ETS area. This decreases as allowance prices increase, reaching approximately $6.3 \%$ at a price of $€ 50 /$ t. Indeed, by examining the non-ETS emissions across different allowance prices, we 


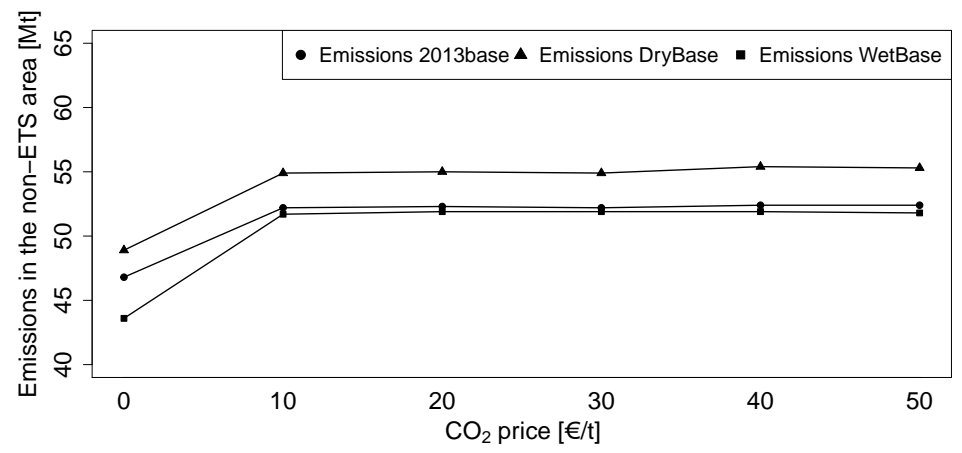

Figure 7: $\mathrm{CO}_{2}$ emissions in the non-ETS area

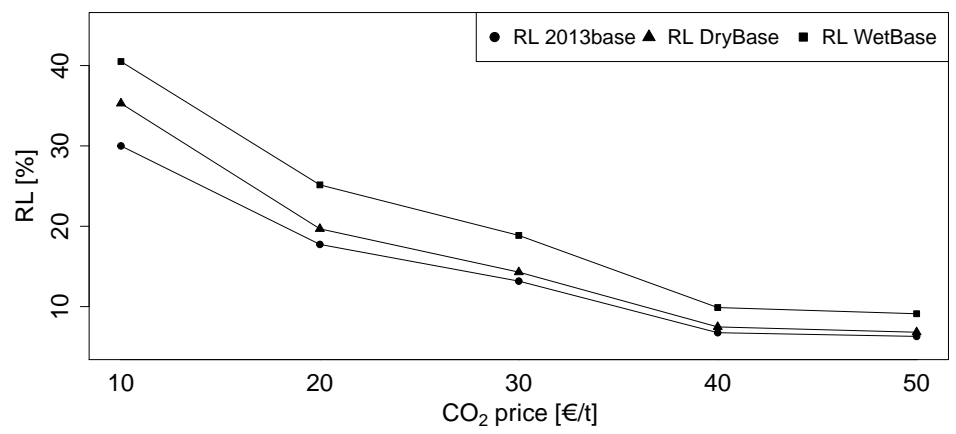

Figure 8: Relative carbon leakage

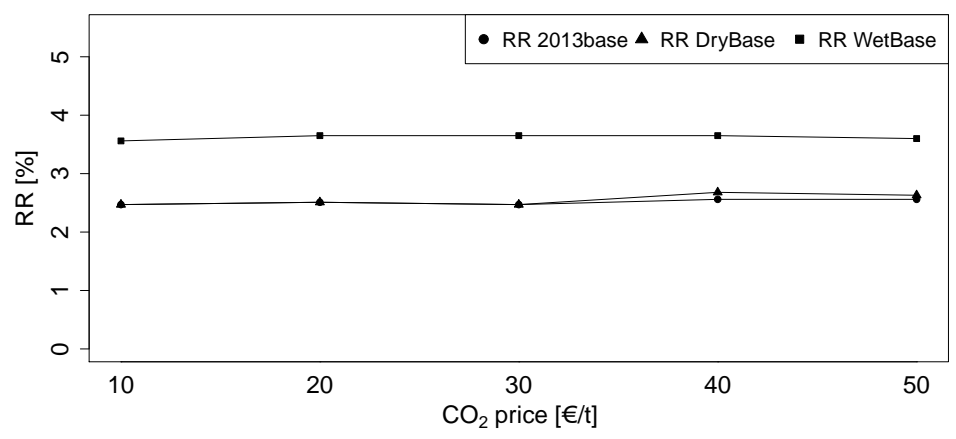

Figure 9: Reduction reversal 
notice that the decline of leakage according to RL is given almost only by the increase in reduction in the ETS area. Although RL provides a useful way of quantifying leakage, its sensitivity to the reduction in the ETS area (along with relatively low installed capacity in the non-ETS area) renders it difficult to discern effects on leakage other than the reduction in the ETS area. In fact, if we examine the RR measure, which is not sensitive to the reduction in the ETS area, then we can see that there might be other effects causing the decrease in leakage such as the demand response in the non-ETS area (explained in detail in Section 4.5.1).

\section{Conclusions}

In the fight against climate change, a variety of policy instruments has been developed with the aim of reducing the GHG emissions. One of the most utilised instruments is the C\&T scheme, e.g., EU ETS. In a C\&T scheme, a cap on emissions in a certain area is imposed through the allocation of emissions allowances to producers who can then trade these allowances among themselves. Achieving objectives under such schemes might be delayed due to their jurisdictional coverage. Specifically, a high price of emissions allowances implies a high marginal abatement cost and a high power price when firms internalise emission cost even if the allowances are grandfathered. The higher power prices in the regulated region provide economic incentives for producers located in the neighbouring non-regulated areas to export to the regulated area, thereby causing carbon leakage. Carbon leakage has previously been examined in the context of the USA and New Zealand markets; however, to the best of our knowledge, a study of carbon leakage in the context of the SEE-REM has not been carried out yet.

We use SEE-REM, a simplified 22-node stylised network system, to study a hydro-abundant regional power market with inconsistent $\mathrm{CO}_{2}$ policies. Our focus is on short-term estimates of carbon leakage, i.e., not considering the possibility of changes in capacity. Due to the fact that SEE-REM is relatively small compared to the entire EU ETS, the allowance prices, in 
addition to amount of hydropower, are treated exogenously to the model, thereby ignoring the interactions between hydropower availability and allowance price. With those assumptions, we implicitly assume that any increase in emissions in the ETS part of SEE-REM will be offset elsewhere in the remaining EU ETS. Finally, we make an implicit assumption that the allowances are allocated through auction with prices equal to the permit prices obtained by the models, ${ }^{11}$ as it is the case in the EU ETS, and that the price of allowances is equal to the assumed carbon price in our scenarios.

Through the examination of the EU ETS in SEE-REM taking into account different allowance prices and hydropower availability scenarios, we have three main findings. First, from reduction reversal we find that carbon leakage may be limited by demand response in the non-ETS area as a result of higher domestic electricity prices. Second, ETS emissions may be higher in the wet year than in the baseline year due to demand response in the ETS area as a result of lower electricity prices. Third, according to relative leakage, between $6.3 \%$ to $40.5 \%$ of the reduction achieved in the SEE-REM ETS area could be leaked to the SEE-REM non-ETS area. These findings indicate the possibility of undesirable outcomes resulting from the EU ETS on the periphery of the EU, i.e., emissions leaked into the non-ETS part of SEE-REM, which lead to higher electricity prices in that part. However, similar to the U.S. Clean Air Act IV $\mathrm{SO}_{2}$ trading program, the initial design of the program partly reflects the intention of the government to ensure "buy-in" of the energy sector. Incomplete coverage of the EU ETS, while worrisome to economists, does pave a pathway that allows for a gradual expansion of the ETS in the future to enhance its efficacy.

The findings in this paper are limited to the assumptions related to the considered model and data implementation. First, we model only residual demand and make an assumption that the producers are perfectly competitive, and, thus, we do not take into account the ownership structure. This means that any market power that producers might have is not

\footnotetext{
${ }^{11}$ Alternative allocation mechanisms impact carbon leakage differently. It has often been observed that, e.g., output-based allocation could effectively lower the marginal cost of production, thereby mitigating leakage (Bushnell and Chen, 2012; Burtraw et al., 2006).
} 
reflected in the model. Second, we make an assumption that the consumers are represented by price-responsive demand with elasticity of -0.25 and face nodal prices, which in some cases, leads to a decrease in carbon leakage. This means that when receiving a price signal at the relevant node, consumers will respond. In reality, electricity prices in Europe are frequently given by zonal, uniform, or tariff prices and are often fixed for a period of time, which means that consumers would not be able to react so quickly to the change in nodal prices. In addition, in reality, short-run demand might be more inelastic, which means that demand response to higher electricity prices might be lower in reality. Thus, the decrease in leakage according to reduction reversal that occurs as a result of demand response in the model might be overestimated. On the other hand, since the decrease in leakage according to relative leakage depends mostly on the reduction in the ETS area, relative leakage is more robust vis-à-vis the elasticity assumption. Finally, the model does not include any dynamic power plant constraints, which might affect the resulting generation mix.

For future work, it would be interesting to examine carbon leakage in an imperfect competition setting. This could be carried out by including hydro and renewable power producers in the model in order to account for all market participants who might have market power. For realistically accounting for hydro and renewable electricity generation, the model would have to include hydro scheduling (Bushnell, 2003) and stochastic scenarios for wind production (Maurovich-Horvat et al., 2015). Furthermore, we could include an additional constraint for zonal pricing and consider different values for elasticity. Finally, a capacity-investment model would be needed to provide insights about the long-term effects of a C\&T policy on carbon leakage.

\section{Acknowledgements}

We are grateful to the editor and two anonymous referees for helpful suggestions that have improved the paper. Feedback from participants of the 2015 INFORMS Annual Meeting, the 2016 IAEE International Conference, and a seminar at HEC Montréal has also enhanced 
our work. We have especially benefited from discussions with Vilma Virasjoki of Aalto University about power system modelling. All remaining errors are the authors' own. Višković acknowledges support from the UCL Centre for Doctoral Training in Financial Computing \& Analytics.

\section{References}

Bjørndal, E., Bjørndal, M., and Gribkovskaia, V. (2013). Congestion management in the Nordic power market-Nodal pricing versus zonal pricing. SNF Report 15-12, Institute for Research in Economics and Business Administration, Bergen, Norway. https://brage.bibsys.no/ xmlui/bitstream/handle/11250/165371/R15_12.pdf? sequence=1\&isAllowed=y.

Bjørndal, E., Bjørndal, M., and Hong C. (2014). Nodal pricing in a coupled electricity market $11^{\text {th }}$ International Conference on the European Energy Market (EEM14)

Burtraw, D., Kahn, D., and Palmer, K. (2006). $\mathrm{CO}_{2}$ allowance allocation in the regional greenhouse gas initiative and the effect on electricity investors. The Electricity Journal, 19(2):79-90.

Bushnell, J. (2003). A mixed complementarity model of hydrothermal electricity competition in the Western United States. Operations Research, 51(1):80-93.

Bushnell, J. and Chen, Y. (2012). Allocation and leakage in regional cap-and-trade markets for $\mathrm{CO}_{2}$. Resource and Energy Economics, 34(4):647-668.

Bushnell, J., Chen, Y., and Zaragoza-Watkins, M. (2014). Downstream regulation of $\mathrm{CO}_{2}$ emissions in California's electricity sector. Energy Policy, 64:313-323.

Chen, Y. (2009). Does a regional greenhouse gas policy make sense? A case study of carbon leakage and emissions spillover. Energy Economics, 31(5):667-675.

Chen, Y. and Hobbs, B. F. (2005). An oligopolistic power market model with tradable $\mathrm{NO}_{x}$ permits. Power Systems, IEEE Transactions on, 20(1):119-129. 
Chen, Y., Sijm, J., Hobbs, B. F., and Lise, W. (2008). Implications of $\mathrm{CO}_{2}$ emissions trading for short-run electricity market outcomes in Northwest Europe. Journal of Regulatory Economics, 34(3):251-281.

Dietrich, K., Hennemeier, U., Hetzel, S., Jeske, T., Leuthold, F., Rumiantseva, I., Rummel, H., Sommer, S., Sternberg, C., and Vith, C. (2005). Nodal pricing in the German electricity sector-A welfare economics analysis, with particular reference to implementing offshore wind capacities. Final report of the study project "More wind?". Working Paper WPEM-08, Chair of Energy Economics and Public Sector Management, Dresden University of Technology, Dresden, Germany. https://tu-dresden.de/die_tu_dresden/fakultaeten/ fakultaet_wirtschaftswissenschaften/bwl/ee2/dateien/ordner_publikationen/ wp_ge_08_dietrich_hennemeier_hetzel_etal_nodal_pricing_germany ·pdf.

Downward, A. (2010). Carbon charges in electricity markets with strategic behavior and transmission. The Energy Journal, 31(4):159.

EBRD (2010). Energy sector assessment 2010-Final report. Technical report, European Bank for Reconstruction and Development, London, U.K. http://www.ebrd.com/downloads/ legal/irc/assessment.pdf.

EC (2007). 2020 Energy strategy. European Commission, Brussels, Belgium. https: //ec. europa.eu/energy/en/topics/energy-strategy/2020-energy-strategy.

EC (2009). Carbon leakage. European Commission, Brussels, Belgium. http://ec.europa. eu/clima/policies/ets/cap/leakage/index_en.htm.

EC (2014). 2030 Energy strategy. European Commission, Brussels, Belgium. https: //ec. europa.eu/energy/en/topics/energy-strategy/2030-energy-strategy.

EC (2015). The EU Emissions trading system (EU ETS). European Commission, Brussels, Belgium. http://ec.europa.eu/clima/policies/ets/index_en.htm. 
EC (2015a). Commission staff working document executive summary of the impact assessment. European Commission, Brussels, Belgium. https://ec.europa.eu/energy/sites/ener/ files/documents/1_EN_resume_impact_assessment_part1_v7.pdf.

EC (2015b). Structural reform of the European carbon market. European Commission, Brussels, Belgium. http://ec.europa.eu/clima/policies/ets/reform/index_en.htm.

ECORYS (2013). Carbon leakage evidence project. Technical report for DG Climate Action, ECORYS, Rotterdam, The Netherlands. http://ec.europa.eu/clima/policies/ets/ cap/leakage/docs/cl_evidence_factsheets_en.pdf.

Egerer, J., Gerbaulet, C., Ihlenburg, R., Kunz, F., Reinhard, B., von Hirschhausen, C., Weber, A., and Weibezahn, J. (2014). Electricity sector data for policy-relevant modeling. Data Documentation and Applications to the German and European Electricity Markets, DIW, Berlin, Germany. http://www.diw.de/documents/publikationen/73/diw_01.c . 440963.de/diw_datadoc_2014-072.pdf.

Energy Community (2005). Treaty establishing the Energy Community. Energy Community, Vienna, Austria. https://www.energy-community.org/portal/page/portal/ENC_ HOME/DOCS/2796177/0633975AD6157B9CE053C92FA8C06338. PDF.

ENTSO (2001). Procedures for cross-border transmission capacity assessments. Technical report, European Network of Transmission System Operators, Brussels, Belgium. https://www.entsoe.eu/publications/market-reports/Documents/entsoe_ proceduresCapacityAssessments . pdf.

ENTSO-E (2011). Indicative values for NTC in Continental Europe in winter 2011. ENTSOE, Brussels, Belgium. https://www.entsoe.eu/fileadmin/user_upload/_library/ntc/ archive/NTC-Values-Winter-2010-2011.pdf.

ENTSO-E (2012). Indicative values for NTC in Europe in summer, 2010. ENTSO-E, 
Brussels, Belgium. https://www.entsoe.eu/fileadmin/user_upload/_library/ntc/ archive/NTC_Values_-_Summer-2010.pdf.

ENTSO-E (2013). Yearly statistics and adequacy retrospect. Technical report, ENTSOE, Brussels, Belgium. https://www.entsoe.eu/Documents/Publications/Statistics/ YSAR/141515_YSAR_2013_report.pdf.

EU (2012). Gazzetta ufficiale dell'Unione Europea. European Union, Brussels, Belgium. http://eur-lex.europa.eu/legal-content/IT/TXT/PDF/?uri=0J :L:2012:181: FULL\&from=IT.

Eurostat (2014). Electricity and heat statistics. Eurostat, Luxembourg, Luxembourg. http://ec.europa.eu/eurostat/statistics-explained/index.php/Electricity_ and_heat_statistics.

Gabriel, S. A., Conejo, A. J., Fuller, J. D., Hobbs, B. F., and Ruiz, C. (2012). Complementarity Modeling in Energy Markets. Springer Science \& Business Media, New York, NY, USA.

Gabriel, S. A. and Leuthold, F. U. (2010). Solving discretely-constrained MPEC problems with applications in electric power markets. Energy Economics, 32(1):3-14.

Gillingham, K., Rapson, D., and Wagner, G. (2016). The rebound effect and energy efficiency policy. Review of Environmental Economics and Policy, 10(1):68-88.

Glover, J. D., Sarma, M. S., and Overbye, T. (1987). Power Systems Analysis and Design. Cengage Learning, Boston, MA, USA.

GME (2015). Italian pricing zones. Gestore Mercati Energetici, Rome, Italy. https: //www.mercatoelettrico.org/en/mercati/MercatoElettrico/Zone.aspx.

Green, R. (2007). Nodal pricing of electricity: how much does it cost to get it wrong? Journal of Regulatory Economics, 31(2):125-149. 
Hobbs, B. F. (1995). Optimization methods for electric utility resource planning. European Journal of Operational Research, 83(1):1-20.

Hobbs, B. F. (2001). Linear complementarity models of Nash-Cournot competition in bilateral and POOLCO power markets. IEEE Transactions on Power Systems, 16(2):194-202.

Hyman, L. S. (2010). Restructuring electricity policy and financial models. Energy Economics, $32(4): 751-757$.

IEA (2010). Gas-fired power. Technical report, IEA ETSAP, Paris, France. https:// iea-etsap.org/E-TechDS/PDF/E02-gas_fired_power-GS-AD-gct.pdf.

IEA (2015). $\mathrm{CO}_{2}$ Emissions from fuel combustions Technical report, IEA ETSAP, Paris, France. https://www.iea.org/publications/freepublications/publication/ CO2EmissionsFromFuelCombustionHighlights2015.pdf.

Kolstad, J., and Wolak, F. (2003). Using environmental emissions permit prices to raise electricity prices: Evidence from the California electricity market. Technical report, Center for the Study of Energy Markets.

Limpaitoon, T., Chen, Y., and Oren, S. S. (2011). The impact of carbon cap and trade regulation on congested electricity market equilibrium. Journal of Regulatory Economics, 40(3):237-260.

Limpaitoon, T., Chen, Y., and Oren, S. S. (2014). The impact of imperfect competition in emission permits trading on oligopolistic electricity markets. The Energy Journal, 35(3):145-166.

Maurovich-Horvat, L., Boomsma, T. K., and Siddiqui, A. S. (2015). Transmission and wind investment in a deregulated electricity industry. IEEE Transactions on Power Systems, 30(3):1633-1643. 
Palmer, K., Burtraw, D., and Kahn, D. (2006). Simple rules for targeting $\mathrm{CO}_{2}$ allowance allocations to compensate firms. Climate Policy, 6(4):477-493.

Paul, A., Burtraw, D., and Palmer, K. (2009). HAIKU documentation: RFF's electricity market model VERSION 2.0. Technical report, Resources for the Future, Washington, DC, USA. http://rff.org/RFF/Documents/RFF-Rpt-Haiku.v2.0.pdf.

Reuters (2015). Bulgaria starts test trading at day-ahead power exchange. Reuters, 11 December 2015. http://www.reuters.com/article/ bulgaria-energy-bourse-idUSL8N13Y1NQ20151211.

Rintamäki, T., Siddiqui, A. S., and Salo, A. (2016). How much is enough? Optimal support payments in a renewable-rich power system. Energy, 117:300-313.

Schweppe, F. C., Caramanis, M. C., Tabors, R. D., and Bohn, R. E. (1988). Spot Pricing of Electricity. Springer Science \& Business Media, New York, NY, USA.

Stocker, T., Qin, D., Plattner, G., Tignor, M., Allen, S., Boschung, J., Nauels, A., Xia, Y., Bex, B., and Midgley, B. (2013). Climate change 2013: the physical science basis. Contribution of Working Group I to the Fifth Assessment Report of the Intergovernmental Panel on Climate Change. Cambridge University Press, Cambridge, United Kingdom and New York, NY, USA. http://www.ipcc.ch/report/ar5/wg1/.

Tanaka, M. and Chen, Y. (2013). Market power in renewable portfolio standards. Energy Economics, 39:187-196.

Terna (2011). Caratteristiche generali delle linee elettriche aeree facenti parte della RTN. Terna, Rome, Italy. http://docplayer.it/ 2359751-Note-tecniche-caratteristiche-generali.html.

Terna (2013a). Dati provvisori esercizio 2013. Terna, Rome, Italy. http://download.terna. it/terna/0000/0118/52.pdf 
Terna (2013b). Limiti di transito V18. Terna, Rome, Italy. http://download.terna.it/ terna/0000/0255/90.pdf.

Van den Bergh, K., Delarue, E., and D'haeseleer, W. (2013). Impact of renewables deployment on the $\mathrm{CO}_{2}$ price and the $\mathrm{CO}_{2}$ emissions in the European electricity sector. Energy Policy, 63:1021-1031.

Višković, A., Franki, V., and Valentić, V. (2014). CCS (carbon capture and storage) investment possibility in South East Europe: A case study for Croatia. Energy, 70:325-337.

von Hirschhausen, C. (2014). The German Energiewende-An introduction. Economics of Energy \& Environmental Policy, 3(2).

Weigt, H. (2006). A time-variant welfare economic analysis of a nodal pricing mechanism in Germany. Electricity Markets Working Paper WP-EM-11, TU Dresden, Germany. http://papers.ssrn.com/sol3/papers.cfm?abstract_id=1137403.

Weigt, H., Ellerman, D., and Delarue, E. (2013). $\mathrm{CO}_{2}$ abatement from renewables in the German electricity sector: Does a $\mathrm{CO}_{2}$ price help? Energy Economics, 40:S149-S158.

Wilson, R. (2002). Architecture of power markets. Econometrica, 70(4):1299-1340.

\section{Appendix A Nomenclature}

$$
\begin{array}{ll}
\text { Indices and Sets } \\
i, j \in \mathcal{I} \quad \text { Producers } \\
\ell \in \mathcal{L} \quad \text { Lines } \\
\ell^{A C} \in \mathcal{L}^{A C} \quad \text { AC lines, } \mathcal{L}^{A C} \subseteq \mathcal{L} \\
n, m \in \mathcal{N} \quad \text { Nodes } \\
n^{A C} \in \mathcal{N}^{A C} \text { Nodes part of the AC network, } \mathcal{N}^{A C} \subseteq \mathcal{N} \\
n^{D C} \in \mathcal{N}^{D C} \text { Nodes part of the } \mathrm{DC} \text { network, } \mathcal{N}^{D C} \subseteq \mathcal{N}, \mathcal{N}^{A C} \cup \mathcal{N}^{D C}=\mathcal{N}
\end{array}
$$


$t \in \mathcal{T} \quad$ Time blocks

Parameters

$A_{n, \ell} \quad$ Network incidence matrix, 1 indicates a node where the line starts and -1 a node where the line finishes [-]

$C_{i, n} \quad$ Marginal cost of production for producer $i$ at node $n$ [€/MWh]

$D_{t, n}^{\text {int }} \quad$ Inverse demand intercept at node $n$ for time block $t[€ / \mathrm{MWh}]$

$D_{t, n}^{s l p} \quad$ Inverse demand slope at node $n$ for time block $t\left[€ / \mathrm{MW}^{2} \mathrm{~h}\right]$

$E_{i, n} \quad$ Carbon intensity of production for producer $i$ at node $n$ [t/MWh]

$H_{\ell^{A C}, n^{A C}} \quad$ Element of the network transfer admittance matrix for the line $\ell^{A C} \in \mathcal{L}^{A C}$ that connects nodes $n^{A C} \in \mathcal{N}^{A C}[\mathrm{~S}]$

$K_{\ell} \quad$ Capacity of line $\ell[\mathrm{MW}]$

$N_{t} \quad$ Size of each time block $[\mathrm{h}]$

$R \quad$ Price of emissions allowances $[€ / \mathrm{t}]$

$T_{n} \quad$ Binary parameter equals 1 if node $n$ is in the ETS and 0 otherwise

$X_{i, n}^{M A X} \quad$ Maximum production capacity for producer $i$ at node $n$ [MW]

Z Carbon cap $[\mathrm{t}]$

Dual Variables

$\gamma_{t, \ell^{A C}} \quad$ Dual variable for flow constraint on line $\ell^{A C} \in \mathcal{L}^{A C}$ for time block $t[€ / \mathrm{MW}]$

$\theta_{t, i} \quad$ Dual variable for energy-balance constraint for producer $i$

for time block $t[€ / \mathrm{MW}]$

$\lambda_{t, i, n} \quad$ Dual variable for generation capacity constraint for producer $i$ at node $n$ for time block $t[€ / \mathrm{MW}]$

$\mu_{t, \ell}^{-} \quad$ Dual variable for line capacity constraint, lower bound on line $\ell$ for time block $t[€ / \mathrm{MW}]$ 
$\mu_{t, \ell}^{+} \quad$ Dual variable for line capacity constraint, upper bound on line $\ell$ for time block $t[€ / \mathrm{MW}]$

$\tau_{t, n} \quad$ Dual variable on electricity market-clearing conditions (wheeling fee) at node $n$ for time block $t$ [€/MWh]

\section{Primal Variables}

$d_{t, n^{A C}} \quad$ Voltage angle at node $n^{A C} \in \mathcal{N}^{A C}$ for time block $t[\mathrm{rad}]$

$f_{t, \ell} \quad$ Flow on line $\ell$ for time block $t[\mathrm{MW}]$

$s_{t, i, n} \quad$ Power sold by producer $i$ at node $n$ for time block $t$ [MW]

$x_{t, i, n} \quad$ Power generated by producer $i$ at node $n$ for time block $t$ [MW]

\section{Appendix B Demand Coefficients Calculation}

If the inverse demand function in its general form is given by (B-1), where $p(q)$ is the price in function of the quantity sold and $q$ is the quantity, then $a$ and $b$ are the intercept and the slope of the inverse demand function, respectively.

$$
p(q)=a+b q
$$

The intercept and the slope of the inverse demand function can be calculated using reference price $p^{r e f}$, reference quantity $q^{r e f}$, and elasticity $\epsilon$ (Dietrich et al., 2005), as shown in (B-2) and (B-3), respectively. Considering the granularity of our data, i.e., monthly, if we use (B-2) and (B-3), then we would obtain only one representative hour per month that is based on the monthly average. However, because we want to distinguish between peak and off-peak hours, we use hourly load profile data to calculate the load curve (see Section 4.1.4) 
and then obtain the intercept and slope based on (B-4) and (B-5), respectively.

$$
\begin{aligned}
a & =p^{\text {ref }}-b q^{\text {ref }} \\
b & =\frac{p^{\text {ref }}}{q^{\text {ref }}} \frac{1}{\epsilon} \\
a & =p^{\text {ref }}-b q^{\text {ref }} \text { loadcurve } \\
b & =\frac{p^{\text {ref }}}{q^{\text {ref loadcurve }} \frac{1}{\epsilon}}
\end{aligned}
$$

\section{Appendix C Data for SEE-REM}

\section{C.1 Line-Specific Data in Detail}

Although NTCs are limits on commercial flows between two connecting areas rather than actual thermal limits of the lines, the calculation of the former is based on the latter (ENTSO, 2001). Thus, we use NTCs as an approximation due to the lack of data on actual thermal capacity limits. We distinguish between AC and DC lines, and because power flows on AC lines are subject to both Kirchhoff's laws, we model these flows using DC load-flow approximation. The DC load-flow approximation is obtained from network transfer and susceptance matrices (Schweppe et al., 1988), for which we require line reactance and resistance values (Glover et al., 1987) that depend on the physical characteristics of AC lines (Terna, 2011). Resistance and reactance values are displayed in Table $\mathrm{C}-1$. In addition, we divide the nodes in the network into the ones connected by the AC and DC lines. DC lines do not follow the loop-flow law, and are, thus, not subject to Equation (10). This means that the model does not give solutions for voltage angles at nodes connected by a DC line. Consequently, flows on lines connecting a node in the DC part of the network and a node in the AC part of the network cannot be subject to Equation (10) either. Therefore, flows on these lines are treated like

commercial flows. A similar approach was used by Bjørndal et al. (2014) to model a market consisting of nodal and zonal pricing areas. 


\begin{tabular}{lccc}
\hline $\begin{array}{l}\text { Number } \\
\text { of conductors }\end{array}$ & $\begin{array}{c}\text { Voltage } \\
{[\mathrm{kV}]}\end{array}$ & $\begin{array}{c}\text { Resistance } \\
{[\Omega / \mathrm{km}]}\end{array}$ & $\begin{array}{c}\text { Reactance } \\
{[\Omega / \mathrm{km}]}\end{array}$ \\
\hline 1 & $<380$ & 0.059 & 0.236 \\
3 & $\geq 380$ & 0.019 & 0.078 \\
\hline
\end{tabular}

Table C-1: Line resistance and reactance values (Glover et al. (1987) and own calculation)

\section{C.2 Node-Specific Capacities in Detail}

Since ENTSO-E does not define well the category "mixed fuels," which typically refers to units that can be fired by more than one type of fuel, we adjust the generating capacities in the ENTSO-E's mixed fuel category by using more detailed generation data (Eurostat, 2014) and utility companies' published information about generation capacities. In addition, because we model Italy by eleven nodes, we distribute capacities obtained from ENTSO-E (2013) across nodes based on information about capacities by regions (Terna, 2013a), which we then aggregate into zones as defined by the Italian Power Exchange (IPEX) (GME, 2015). The capacities that we obtain are in Table C-2. 


\begin{tabular}{|c|c|c|c|c|c|c|c|}
\hline Node & Gas & Coal & Oil & CCGT & Nuclear & Lignite & Mixed \\
\hline$n_{1}$ & 1.55 & 1.27 & 1.98 & 16.89 & 0 & 0 & 3.51 \\
\hline$n_{2}$ & 0.57 & 0.11 & 1.12 & 1.48 & 0 & 0 & 0.39 \\
\hline$n_{3}$ & 1.14 & 1.49 & 2.75 & 2.93 & 0 & 0 & 0.15 \\
\hline$n_{4}$ & 0.61 & 0.03 & 0.15 & 5.28 & 0 & 0 & 1.14 \\
\hline$n_{5}$ & 0.13 & 0.89 & 0.55 & 0.43 & 0 & 0 & 0.09 \\
\hline$n_{6}$ & 0.83 & 0 & 1.24 & 1.41 & 0 & 0 & 0.23 \\
\hline$n_{7}$ & 0 & 0.12 & 0.61 & 0 & 0 & 0 & 0 \\
\hline$n_{8}$ & 0.01 & 0 & 0 & 0.30 & 0 & 0 & 0 \\
\hline$n_{9}$ & 0 & 2.64 & 0 & 0.99 & 0 & 0 & 0 \\
\hline$n_{10}$ & 0.65 & 0 & 0.65 & 0 & 0 & 0 & 0 \\
\hline$n_{11}$ & 0 & 0 & 0 & 0.36 & 0 & 0 & 0 \\
\hline$n_{12}$ & 0.08 & 0.22 & 0.15 & 0 & 0.69 & 0.58 & 0.36 \\
\hline$n_{13}$ & 0.42 & 0.32 & 0.49 & 0.19 & 0 & 0 & 0.37 \\
\hline$n_{14}$ & 0 & 0 & 0 & 0 & 0 & 1.57 & 0 \\
\hline$n_{15}$ & 0.31 & 0 & 0 & 0 & 0 & 5.28 & 0 \\
\hline$n_{16}$ & 0 & 0 & 0 & 0 & 0 & 0.22 & 0 \\
\hline$n_{17}$ & 0.03 & 0 & 0.19 & 0 & 0 & 0.72 & 0 \\
\hline$n_{18}$ & 2.72 & 0 & 0.70 & 2.19 & 0 & 4.46 & 0 \\
\hline$n_{19}$ & 0 & 0 & 0 & 0 & 0 & 0 & 0 \\
\hline$n_{20}$ & 2.99 & 0.28 & 0.41 & 1.72 & 1.89 & 0.75 & 0 \\
\hline$n_{21}$ & 0.80 & 1.71 & 0 & 0 & 2.00 & 4.20 & 0 \\
\hline$n_{22}$ & 2.38 & 1.18 & 0 & 0.86 & 1.30 & 5.12 & 0 \\
\hline
\end{tabular}

Table C-2: Installed generation capacity mix per node [GW] 


\section{C.3 Nodal Demand in Detail}

In order to obtain residual demand, we divide the residual monthly consumption by the number of hours in that month in order to obtain residual hourly demand. From this, we have one hour representing the average hourly residual demand per month. Because the standard frequency of reporting consumption data is monthly, we can only represent each month by the average hourly demand in that month by using consumption data. In order to distinguish between peak and off-peak hours, we use load profiles for which we can obtain hourly data. With the help of load profile data, we obtain the load curve for four blocks per month. We aggregate load data so that we obtain hourly load for the whole SEE-REM. Subsequently, we divide every month into four blocks corresponding to base, shoulder, peak, and super-peak loads (Paul et al., 2009) as defined in Table C-3.

\begin{tabular}{lc}
\hline Block & Interval \\
\hline Base load & $\min \{$ load $\}-70^{\text {th }}$ percentile $\{$ load $\}$ \\
Shoulder load & $70^{\text {th }}$ percentile $\{$ load $\}-95^{\text {th }}$ percentile $\{$ load $\}$ \\
Peak load & $95^{\text {th }}$ percentile $\{$ load $\}-99^{\text {th }}$ percentile $\{$ load $\}$ \\
Super-peak load & $99^{\text {th }}$ percentile $\{\operatorname{load}\}-\max \{\operatorname{load}\}$ \\
\hline
\end{tabular}

Table C-3: Intervals corresponding to four blocks

The load curve is given by the ratio of the block average load (over the number of hours in that block) and the monthly average load (over the number of hours in that month). Four load curves for each month are listed in Table C-4. Essentially, the load curve is a multiplier for the reference demand that adds variation to the average demand through inverse demand function coefficients, $D_{t, n}^{i n t}$ and $D_{t, n}^{s l p}$, (see Equations (B-4) and (B-5) in Appendix B). Since the number of hours in each block, $N_{t}$, varies based on the number of days in a month, in Table C-5, we show the number of hours in each of the blocks of 28-day, 30-day, and 31-day months. Demand across Italy is distributed using regional consumption data (Terna, 2013a). 


\begin{tabular}{lcccc}
\hline Block & Base load & Shoulder load & Peak load & Super-peak load \\
\hline Jan & 0.9 & 1.2 & 1.24 & 1.27 \\
Feb & 0.92 & 1.17 & 1.21 & 1.23 \\
Jun & 0.91 & 1.17 & 1.31 & 1.35 \\
Dec & 0.90 & 1.21 & 1.30 & 1.34 \\
\hline
\end{tabular}

Table C-4: Load curve for block per month

\begin{tabular}{lccc}
\hline & \multicolumn{3}{c}{ Number of days in month } \\
Blocks & 31 & 28 & 30 \\
\hline Base load & 520 & 470 & 504 \\
Shoulder load & 186 & 168 & 180 \\
Peak load & 30 & 27 & 28 \\
Super-peak load & 8 & 7 & 8 \\
\hline
\end{tabular}

Table C-5: Number of hours per block

\begin{tabular}{lcc}
\hline Fuel & $\begin{array}{c}\text { Cost } \\
{[€ / \mathrm{MWh}]}\end{array}$ & $\begin{array}{c}\text { Emission Intensity } \\
{[\mathrm{t} / \mathrm{MWh}]}\end{array}$ \\
\hline Lignite & 21.0 & 0.826 \\
Coal & 22.0 & 0.746 \\
Nuclear & 10.0 & 0.000 \\
Oil & 50.0 & 0.930 \\
Natural Gas - steam turbine & 47.3 & 0.435 \\
CCGT & 35.7 & 0.363 \\
Mixed fuels & 48.0 & 0.800 \\
\hline
\end{tabular}

Table C-6: Marginal cost of production per fuel and emission intensity

\section{C.4 Electricity Prices}

The data for Italy, Slovenia, and Greece are available from IPEX's Website where Slovenia and Greece are virtual zones. Data for Hungary are available from the Hungarian Power Exchange (HUPX), and data for Romania are on the Romanian electricity and gas market operator's (OPCOM) Website. Although there are some other countries in SEE-REM that 
have day-ahead markets, since these markets did not exist in 2013, e.g., Bulgaria launched its Independent Energy Exchange only in 2015 (Reuters, 2015), we exclude them from our analysis.

Electricity prices derived from the inverse demand function (in the baseline scenario) correspond to generation quantities associated with residual demand. Therefore, these prices are not directly comparable to actual market electricity prices that correspond to total demand under the assumed value of elasticity. Thus, for the purpose of more direct comparison, we adjust the actual prices by rearranging Equation (C-1) in order to preserve the assumed elasticity. Here, $\epsilon$ stands for elasticity, $p$ for price of electricity, and $q$ for generated quantity. Furthermore, $\delta q$ represents the difference between the total and residual quantity, and $\delta p$ is the difference between prices corresponding to those two quantities.

$$
\epsilon=\frac{\delta q}{\delta p} \frac{p}{q}
$$

